\title{
Estimating Hysteresis Effects
}

\author{
Francesco Furlanetto, Antoine Lepetit, Ørjan Robstad, \\ Juan Rubio-Ramírez, and Pål Ulvedal
}

\author{
Working Paper 2021-24 \\ November 2021
}

\begin{abstract}
In this paper, we identify demand shocks that can have a permanent effect on output through hysteresis effects. We call these shocks permanent demand shocks. They are found to be quantitatively important in the United States, in particular when the sample includes the Great Recession. Recessions driven by permanent demand shocks lead to a permanent decline in employment and investment, although output per worker is largely unaffected. We find strong evidence that hysteresis transmits through a rise in long-term unemployment and a decline in labor force participation and disproportionately affects the least productive workers.
\end{abstract}

JEL classification: C32, E24, E32

Key words: hysteresis, structural vector autoregressions, sign restrictions, long-run restrictions, employment, labor productivity, local projections

https://doi.org/10.29338/wp2021-24

First Draft: September 2020. This working paper should not be reported as representing the views of Norges Bank, the Board of Governors of the Federal Reserve System, or the Federal Reserve Bank of Atlanta. The views expressed are those of the authors and do not necessarily reflect those of Norges Bank or of the Federal Reserve System. Any remaining errors are the authors' responsibility. The authors would like to thank for useful comments one anonymous referee for the Norges Bank working paper series, Knut Are Aastveit, Jonas Arias, Drago Bergholt, Saroj Bhattarai, Olivier Blanchard, Paolo Bonomolo, Jeff Campbell, Fabio Canova, Yoosoon Chang, Larry Christiano, Todd Clark, Olivier Coibion, Thorsten Drautzburg, Martin Eichenbaum, Stefano Eusepi, Luca Fosso, Luca Gambetti, Cooper Howes, Michel Juillard, Kurt Lunsford, Christian Matthes, Elmar Mertens, Silvia Miranda Agrippino, Nicoló Maffei Faccioli, Florens Odendhal, Francesco Ravazzolo, Øistein Røisland, Aysegul Sahin, Samad Sarferaz, Tatevik Sekhposyan, Sanjay Singh, Anders Vredin, and Hans Christian Wika. They also thank seminar participants at Boston College, the Federal Reserve Bank of Cleveland, Norges Bank, University of Texas-Austin, Texas A\&M University, Indiana University, Sveriges Riksbank, Friendly Faces Online seminar series, the 20th Computing in Economics and Finance Conference in 0ttawa in June 2019, the 15th Dynare Conference in Lausanne, the sixth Conference on New Developments in Business Cycle Analysis at Norges Bank, the 28th virtual Society for Nonlinear Dynamics and Econometrics conference in Zagreb and the 2021 International Association for Applied Econometrics conference in Rotterdam.

Please address questions regarding content to Francesco Furlanetto, Norges Bank and BI Norwegian Business School, Bankplassen 2, PB 1179 Sentrum, 0107 0slo, Norway, francesco.furlanetto@norges-bank.no; Antoine Lepetit, Board of Governors of the Federal Reserve System, antoine.lepetit@frb.gov; Ørjan Robstad, Norges Bank, ,orjan.robstad@norgesbank.no; Juan Rubio-Ramírez, Emory University, FEDEA, Federal Reserve Bank of Atlanta, and BBVA Research, juan.rubioramirez@emory.edu; or Pål Ulvedal, Norges Bank, pal-bergset.ulvedal@norges-bank.no. Federal Reserve Bank of Atlanta working papers, including revised versions, are available on the Atlanta Fed's website at www.frbatlanta.org. Click "Publications" and then "Working Papers." To receive e-mail notifications about new papers, use frbatlanta.org/forms/subscribe. 


\section{Introduction}

Macroeconomists are used to decomposing output per capita into an upward stochastic trend, often thought of as determining potential output or productive capacity, and the transitory fluctuations around it, often interpreted as business cycles. According to the traditional view, unexpected changes to the trend are caused only by supply shocks, such as labor supply and total factor productivity (TFP) shocks, while the business cycle is mostly driven by shocks to the components of aggregate demand and monetary policy. Blanchard (2018) argues that the assumption that productive capacity is independent from demand shocks in general, and monetary policy in particular, has become the dominant paradigm in macroeconomics and is the basis of the inflation-targeting framework used by most central banks. The "independence assumption" is embedded in the standard toolkit of modern macroeconomic analysis. In fact, most dynamic stochastic general equilibrium (DSGE) models imply that demand shocks have either no or a small transitory effect on the trend (cf. Blanchard, 2018) and structural vector autoregressions (SVAR) are often identified assuming only one shock with permanent effects on output (cf. Blanchard and Quah, 1989). This shock is commonly interpreted as a supply shock.

One alternative (and minority) view, popularized by Blanchard and Summers (1986) in the 1980s, states that demand shocks (especially when causing large recessions) may have a permanent effect on potential output through hysteresis effects. Economic developments in Europe in the 1980s seemed to support the hysteresis view since unemployment was stabilizing at a higher level following each recession. ${ }^{1}$ However, the Great Moderation was interpreted by many economists as supportive of the traditional view, and research on hysteresis largely disappeared. The idea that recessions may have permanent effects on output has re-emerged in the aftermath of the Great Recession as estimates of potential output have been revised down continuously over several years. As of today, the debate is not closed. Supporters of the traditional view argue that the downward revisions mainly reflect lower pre-existing trends masked by the boom in the pre-Great Recession period (cf. Gordon, 2015; Fernald et al., 2017; Antolin-Diaz et al., 2017; Eo and Morley, 2020). In contrast, Summers (2014) interprets them as evidence of hysteresis and stated that "any reasonable reader of the data has to recognize that the financial crisis has confirmed the doctrine of hysteresis more strongly than anyone could have anticipated."

In order to wind up the debate, we use U.S. data on output per capita (output) growth, inflation, employment-to-population (employment) growth, and investment per capita (investment) growth for the period 1983:Q1-2019:Q4 to identify an SVAR that allows for two shocks with potentially permanent effects on output: a traditional supply shock and a more novel demand shock that we disentangle on the basis of the short-run co-movement between output growth and inflation as advocated by Summers (2015). We

\footnotetext{
${ }^{1}$ Such a hysteretic effect of economic fluctuations on the level of unemployment can result from business cycle asymmetries, as in the plucking model of Dupraz et al. (2019).
} 
also allow for two transitory shocks; a demand and a supply shock with no permanent effects on either output or employment. In practice, we combine long-run zero and shortrun sign restrictions to identify the four shocks using the methodology proposed by Arias et al. (2018). We focus our attention on the demand shock with potentially permanent effects, evaluate its importance for economic fluctuations, and analyze its transmission mechanism. The more important this shock is, the larger are the deviations from the independence assumption and the larger is the role for hysteresis effects.

Our main result is on the relevance of hysteresis effects. First, we find that demand shocks with potentially permanent effects do indeed lead to a permanent decrease in output. Thus, from then on, we simply call them permanent demand shocks. Second, we find that these shocks explain more than 50 percent of the fluctuations in long-run output growth. Such a relevant role for permanent demand shocks highlights that the traditional view is not supported by the data. Permanent demand shocks also have important negative permanent effects on prices, employment, and investment.

Our second result is related to the transmission mechanism of hysteresis effects. A permanent decline in output can be conveniently decomposed into an effect on employment and an effect on output per worker. Our impulse response functions (IRFs) show that hysteresis propagates almost exclusively through employment. Output per worker, which can be interpreted as a simple measure of labor productivity, is hardly affected at all, both in the short run and in the long run. Using local projection (LP) methods, we show that the permanent decline in employment is accompanied by an increase in long-term unemployment, a decline in participation, and an increase in applications (and awards) for disability insurance. These responses are consistent with standard hysteresis channels and compatible with the skill depreciation and reduced employability of long-term unemployed workers. When it comes to the neutral long-run effect on labor productivity, the LP approach shows that it is likely the outcome of compensating effects. The share of employment in routine (see Jaimovich and Siu, 2020; Fernández-Villaverde et al., 2019), and arguably less productive, tasks decreases in response to a negative permanent demand shock. This pushes up labor productivity but is compensated by a decrease in both capital intensity and TFP (arguably related to the negative permanent effects on investment). Our results seem to indicate that these two forces cancel each other, leaving output per worker largely unaffected after a permanent demand shock. ${ }^{2}$ Notably, while invariant to permanent demand shocks, output per worker responds strongly to a permanent supply shock. Therefore, our results are consistent with supply shocks being the only drivers of

\footnotetext{
${ }^{2}$ Several recent papers use New Keynesian models with endogenous growth to examine the hypothesis that the slowdown in productivity following the Great Recession was to a large extent an endogenous response to the collapse in demand that caused the contraction in economic activity. See Benigno and Fornaro (2018), Guerron-Quintana and Jinnai (2019), Ikeda and Kurozumi (2019), Moran and Queralto (2018), Bianchi et al. (2019), Anzoategui et al. (2019), and Garga and Singh (2021). Similar mechanisms are also present in agent-based models, as discussed in Dosi et al. (2018). Our evidence is consistent with this literature: a collapse in R\&D investment in the short run is followed by a decline in TFP in the long run.
} 
labor productivity in the long run, as assumed in Galí (1999).

We contribute to the empirical literature on hysteresis (cf. Cerra et al., 2020, for a recent detailed survey). Most studies restrict their attention to deep recessions and investigate their impact on the economy's productive capacity. Cerra and Saxena (2008) find evidence of highly persistent effects on output. Since recessions are not necessarily all driven by demand shocks, Blanchard et al. (2015) focus on 22 recessions associated with intentional disinflations, mostly concentrated during the 1980s and early 1990s. These recessions are driven by large monetary policy shocks that reflect mainly a surprise change in policy rather than the policy response to other shocks. They find that nearly two-thirds of these recessions are associated with a permanently lower output level and that a significant fraction of those are associated with permanently lower output growth. Our paper also connects with SVAR studies on labor market dynamics in the U.S. (cf. Galí and Hammour, 1992), in Scandinavian countries (cf. Jacobson et al., 1997), in Italy (Gambetti and Pistoresi, 2004), and in Spain (Dolado and Jimeno, 1997). None of these papers combine zero and sign restrictions to identify shocks. Notably, sign restrictions were introduced well after (cf. Faust, 1998; Canova and De Nicoló, 2002; Uhlig, 2005; Rubio-Ramirez et al., 2010) and the combination of sign and zero restrictions has become feasible only with the routines recently developed by Arias et al. (2018). In a very recent paper, Benati and Lubik (2021) estimate a cointegrated SVAR for the U.S., the U.K. and the Euro area and find some weak evidence of hysteresis only in the case of the U.K. Finally, while we consider demand shocks with long-run effects on output, Maffei Faccioli (2020) studies the impact of demand factors on output growth (an effect named by Ball, 2014, as super-hysteresis) in an SVAR with common trends and finds supportive evidence.

The paper proceeds as follows. Section 2 provides a brief description of our empirical set-up. Section 3 presents our main results. Section 4 relates our results to the jobless recoveries observed since the 1980s. Section 5 discusses the channels of hysteresis effects. Section 6 investigates the robustness of our results. Finally, section 7 concludes.

\section{The Model}

We consider the standard reduced-form VAR model:

$$
\mathbf{y}_{t}=\mathbf{C}_{B}+\sum_{i=1}^{P} \mathbf{B}_{i} \mathbf{y}_{t-i}+\mathbf{u}_{t}
$$

where $\mathbf{y}_{t}$ is an $N \times 1$ vector containing our $N$ endogenous variables, $\mathbf{C}_{B}$ is an $N \times 1$ vector of constants, $\mathbf{B}_{i}$ for $i=1, \ldots, P$ are $N \times N$ parameter matrices, with $P$ the number of lags ( 4 in our specific case), and $\mathbf{u}_{t}$ the vector of innovations with $\mathbf{u}_{t} \sim N(0, \boldsymbol{\Sigma})$, where $\boldsymbol{\Sigma}$ is the $N \times N$ variance-covariance matrix. We rely on long-run zero and short-run sign restrictions to identify the shocks. We implement the restrictions using the algorithm 
proposed by Arias et al. (2018). ${ }^{3}$

We combine the standard Minnesota prior with the sum-of-coefficients prior (Doan et al., 1984). This combination of priors will reduce overfitting for both the parameters that drive the temporary fluctuations and the underlying deterministic trend in the reducedform VAR (initial conditions). Restraining the role of the initial conditions could be of great importance when trying to assess the long-run effects of demand and supply shocks. We follow Giannone et al. (2015) in the choice of hyperparameters. We use averages from 1949 to the beginning of our estimation sample as the dummy initial observation in the sum-of-coefficients prior, while the Minnesota prior is centered around the variables being independently and identically distributed.

We use quarterly U.S. data on real GDP per capita (output), PCE deflator (prices), employment-to-population ratio (employment) and real investment per capita (investment) over the sample period 1983:Q1-2019:Q4. All variables enter our model in first differences. Since SVAR models identified with long-run restrictions are sensitive to trend breaks and low-frequency correlations (cf. Fernald, 2007), we have chosen to focus on a relatively homogeneous sample. We follow Galí (1999) and use data in first differences in order to allow for (without imposing) hysteresis effects on employment. A specification in levels would tilt the IRFs to converge back to zero, thus making hysteresis effects immaterial (at least in the long run). Nonetheless, we consider a specification with employment (instead of employment growth) in Section 6; our results survive. We consider four lags. Two shocks are transitory, while the remaining two are allowed to have permanent effects. We note that data on (detrended) unemployment, rather than on the employmentto-population ratio, are used in Blanchard and Quah (1989). Our choice is based on the fact that the unemployment rate has recovered (albeit slowly) to its pre-Great Recession level, while the employment-to-population ratio has not. Therefore, it seems more fruitful to search for hysteresis effects by looking at employment data (cf. Yagan, 2019).

The identification assumptions are summarized in Table 1. We assume that there are two transitory shocks that have a zero long-run impact on output (as in Blanchard and Quah, 1989) and employment, thus implying that labor productivity is not affected in the long run by these two transitory shocks. While it is useful in sharpening identification, the long-run restriction on employment does not drive our results. We disentangle the two transitory shocks on the basis of the short-run contemporaneous co-movement between output growth and inflation: a transitory demand shock moves the two variables in the same direction, while a transitory supply shock moves them in the opposite direction. The long-run impact of the remaining two shocks is left unrestricted but the same contemporaneous sign restriction on the co-movement between output growth and inflation is used to classify them as demand or supply shocks. Thus, we identify a traditional supply shock with potentially long-run effects together with a more novel demand shock with also po-

\footnotetext{
${ }^{3}$ In the appendix we replicate the original analysis by Blanchard and Quah (1989) in our framework and recover their results when using their data.
} 
Table 1: Identifying restrictions

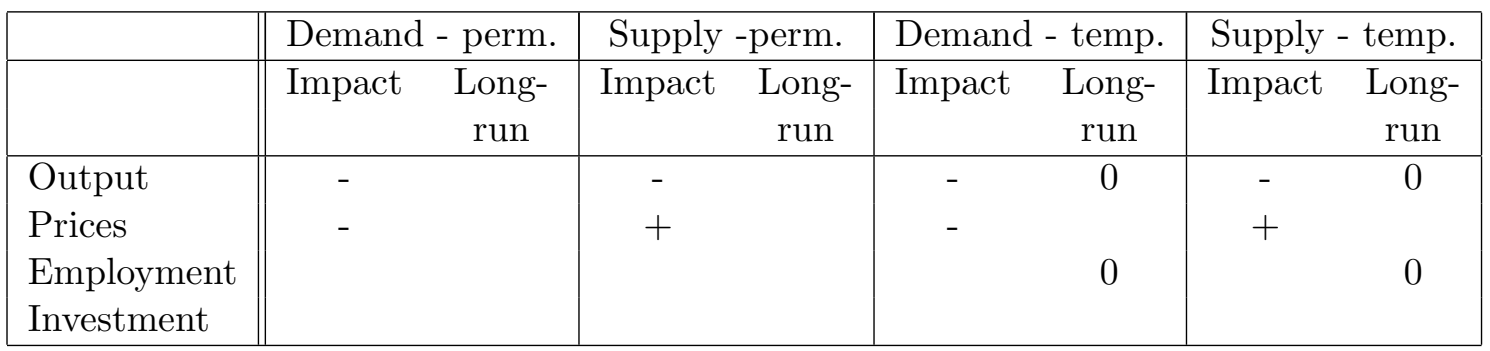

Note: Impact restrictions are imposed on the first difference of the variable, while long-run restrictions are imposed on the level of the variable.

tentially long-run effects, as suggested by Summers (2015). It should be clear that we do not impose the condition that these two shocks have any long-run effects; we only allow for such a possibility. As we will see below, they both have, in fact, permanent effects. For this reason, we will be calling them permanent demand and permanent supply shocks in the rest of the paper. All sign restrictions are imposed on impact, as recommended in Canova and Paustian (2011). Finally, investment is left unrestricted, which allows us to investigate the strength of the investment channel emphasized by Benigno and Fornaro (2018).

A word of caution on the identification strategy needs to be added here. It should not be taken for granted that a negative permanent supply shock should lead to an increase in inflation on impact. It is possible to find parameterizations of the standard New Keynesian model under which a negative permanent technology shock leads to a decrease in inflation (cf. Galí et al., 2003, among others). However, the overwhelming majority of estimated New Keynesian models and SVAR models find a positive response of inflation to a contractionary permanent technology shock (cf. Christiano et al., 2003; Galí and Rabanal, 2004; Basu et al., 2006; Paciello, 2011; Altig et al., 2011, among others). More generally, since it is possible to construct knife-edge cases in which our restrictions are not satisfied on impact, we estimate in the appendix a specification in which restrictions are imposed at horizon four; our results are even stronger in such a case.

In the literature, hysteresis effects are often associated with recessions and not with booms. We note, however, that Ball et al. (1999) and, more recently, Aaronson et al. (2019) and Bluedorn and Leigh (2019) provide evidence of positive hysteresis where permanent decreases in unemployment are associated with protracted expansions. In light of these results, our model's linear structure, although admittedly simple, seems to be a reasonable starting point to search for hysteresis effects.

\section{Finding Hysteresis}

In this section, we present our results. In Figure 1, we plot cumulative IRFs to both the permanent demand and supply shocks. All IRFs plotted in the paper are in response to 
one standard deviation negative (contractionary) shocks. The solid line represents the posterior median at each horizon and the shaded area indicates the 16th and 84th percentiles obtained from the set of IRFs consistent with our identification assumptions. In Figure 2, we present the cumulative forecast error variance decomposition (FEVD) based on the point-wise median posterior estimate. Because we report cumulative IRFs and FEVDs, the analysis is over the level of the variable, not the growth rate.

Two main results stand out. First, permanent demand shocks are important drivers of output fluctuations: they account for more than 50 percent of output variations at all horizons. While permanent supply shocks are also important drivers of output, they play a more minor, yet not negligible, role. Second, we find that the output response to a permanent demand shock is surprisingly similar to the response to a permanent supply shock. Importantly, these similar dynamics are not the result of weakly identified shocks. The response of prices to the two shocks is substantially different despite being restricted only on impact. In addition, the decomposition of output between employment and output per worker also reveals clear differences. The permanent demand shock propagates almost only through employment and both IRFs and FEVD indicate that employment is explained almost exclusively by permanent demand shocks in the long run. In contrast, the permanent supply shock propagates mainly through output per worker; both IRFs and FEVD indicate that output per worker is explained almost exclusively by permanent supply shocks in the long run. This result supports the identification scheme proposed by Galí (1999) to identify technology shocks in an SVAR where only one shock can have permanent effects on labor productivity. ${ }^{4}$

We also find that investment drops permanently in response to both shocks. While such a behavior of investment in response to permanent supply shocks is not surprising, standard theories of the business cycle predict that the drop in investment in response to demand shocks should only be temporary. However, the observed response of investment to permanent demand shocks is consistent with channels emphasized by Benigno and Fornaro (2018), where the interaction of endogenous growth and the zero lower bound on nominal interest rates can lead to prolonged periods of high unemployment and low growth, or Kozlowski et al. (2020), where the occurrence of extreme events such as the Great Recession generates persistent changes in beliefs and macroeconomic outcomes.

Summarizing, our results show that hysteresis effects are large. In particular, a negative permanent demand shock leads to a permanent decline in output and employment and this shock is an important driver of output fluctuations and the main driver of employment fluctuations, both at short and long horizons. The fact that hysteresis effects propagate

\footnotetext{
${ }^{4}$ Unlike in Blanchard and Quah (1989) and Galí (1999), whose samples cover the 1950s to the 1970s, our permanent permanent supply shock generates co-movement between output and employment. Galí et al. (2003) also find that the response of hours to a permanent supply shock switches sign in the VolckerGreenspan period and argue that it is related to a change in the conduct of monetary policy. Moreover, our permanent supply shock can capture forces other than technology such as labor supply or tax shocks, as in Mertens and Ravn (2011).
} 
Figure 1: IRFs to the permanent demand and supply shocks
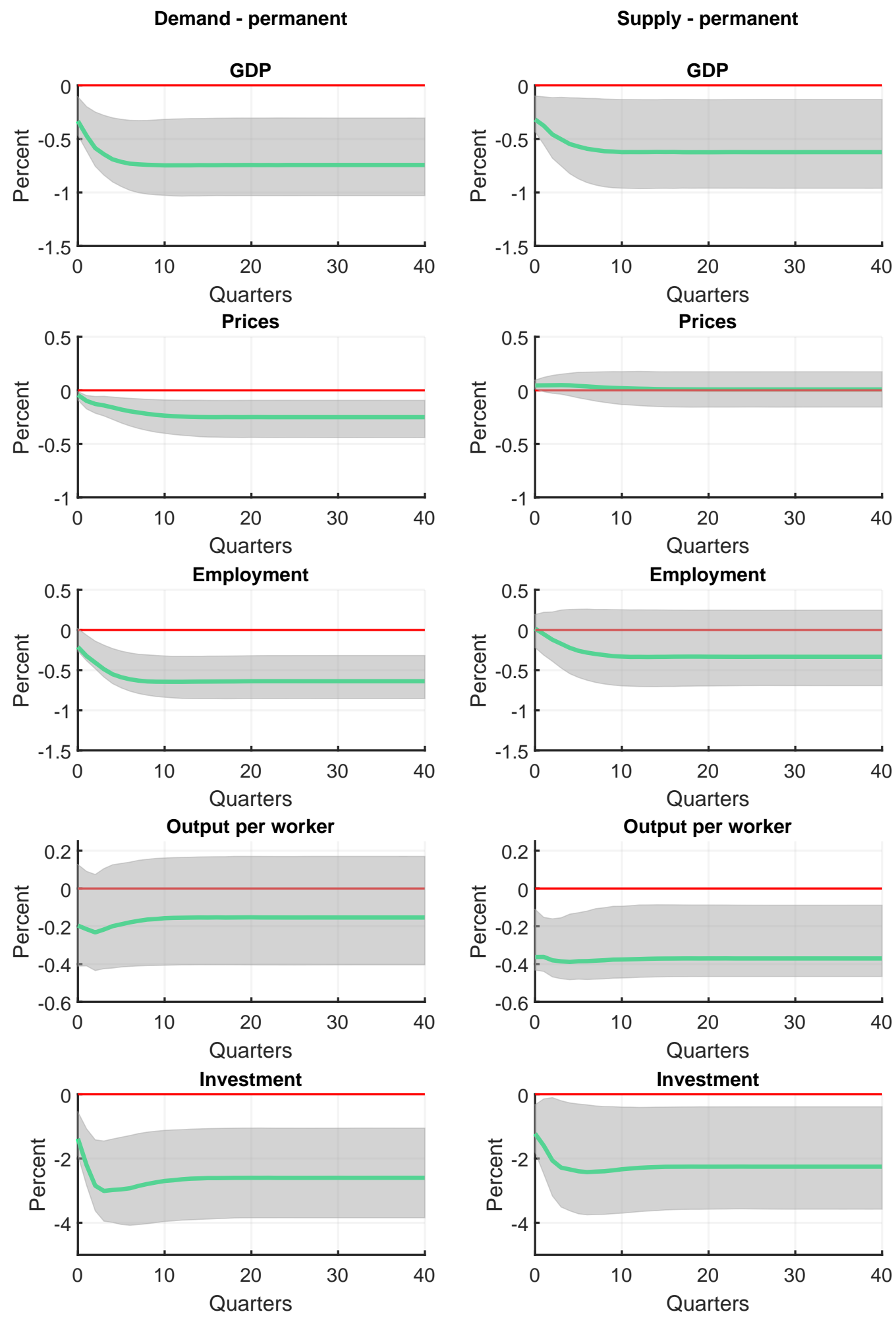
Figure 2: Forecast error variance decomposition
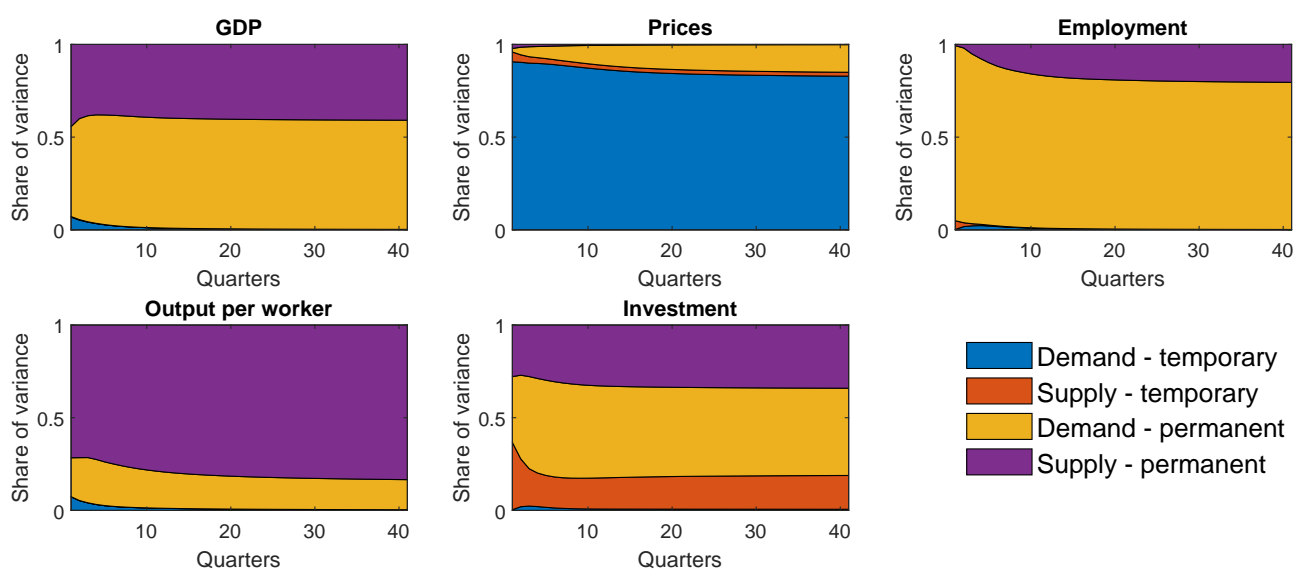

mainly through employment while leaving labor productivity unchanged is a defining feature of our results.

We now briefly comment on transitory shocks whose cumulative IRFs are presented in the appendix. The transitory supply shock marginally explains price and investment fluctuations. Transitory demand shocks induce a small fraction of output fluctuations but are the main drivers of fluctuations in prices at all horizons. This finding is consistent with evidence on the orthogonal response of prices to the business cycle since the 1990s (see, for example, Del Negro et al., 2020, among many others): inflation is driven by its own shock (our transitory demand shock) and this shock has little effect on real variables. ${ }^{5}$ The limited role of transitory shocks is discussed further in Section 6.

In Figure 3 we present a historical decomposition for output growth (in deviation from its forecastable component) into the contribution of the four shocks. The conclusion is that permanent demand shocks are dominant in recessions. To reinforce that point, Figure 4 runs counterfactuals for output over the three recessions in our sample. The left column shows how output would have behaved in the absence of permanent demand shocks in the recessions of 1991, 2001, and 2008. The right column performs the same exercise in the absence of permanent supply shocks. Clearly, permanent demand shocks are the more important driver of these three recessions.

It is also worthwhile to note that while permanent supply shocks are not important drivers of recessions in our sample, they contribute significantly to the sustained output growth of the late 1990s, in line with the high productivity growth in that period. Finally, and consistent with the results described above, transitory demand shocks explain a very small fraction of unexpected fluctuations in output.

\footnotetext{
${ }^{5}$ Angeletos et al. (2020) similarly find that shocks explaining the bulk of fluctuations in real activity explain very little of movements in inflation, and vice versa.
} 
Figure 3: Historical decomposition of the growth rate in GDP per capita

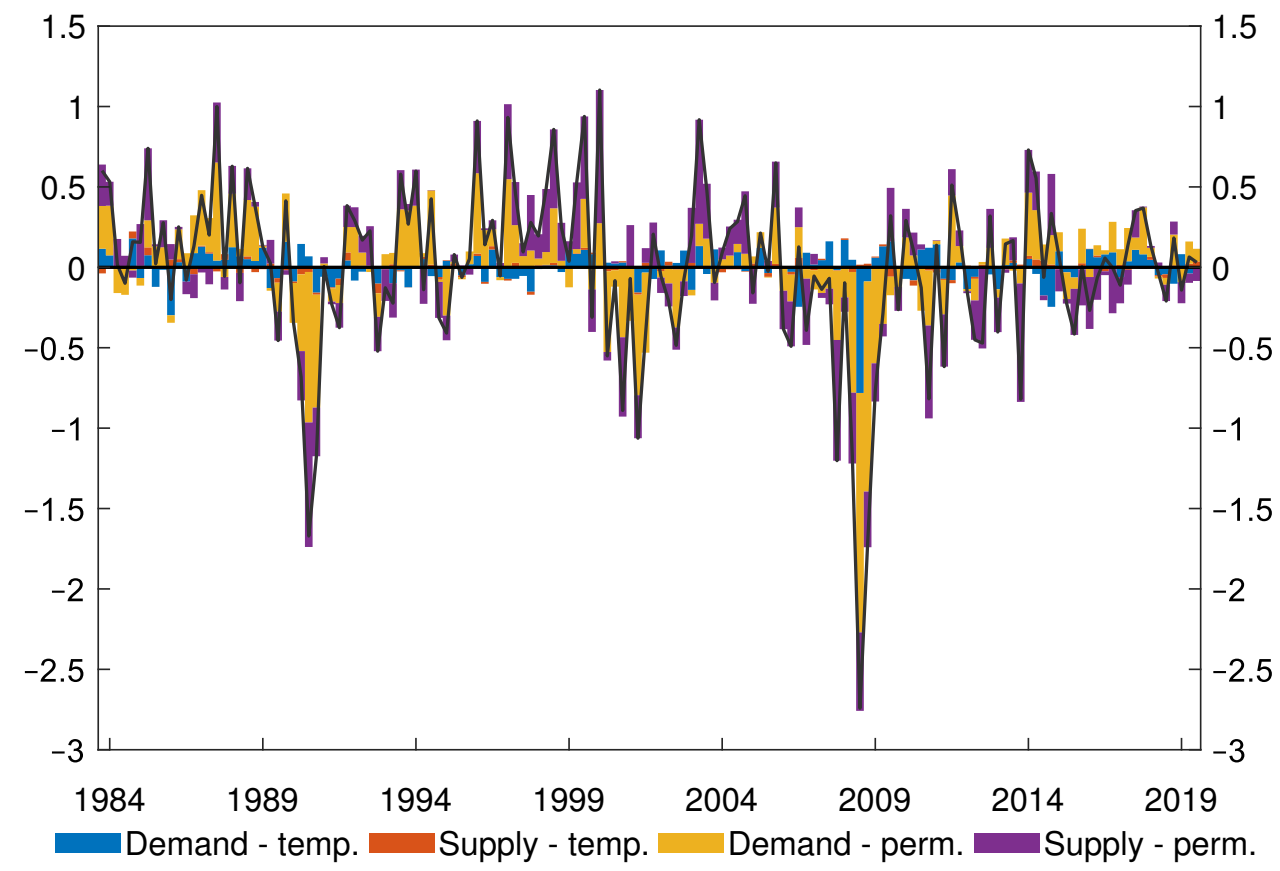

Figure 4: Counterfactual path of output in recessions in the absence of permanent demand and supply shocks
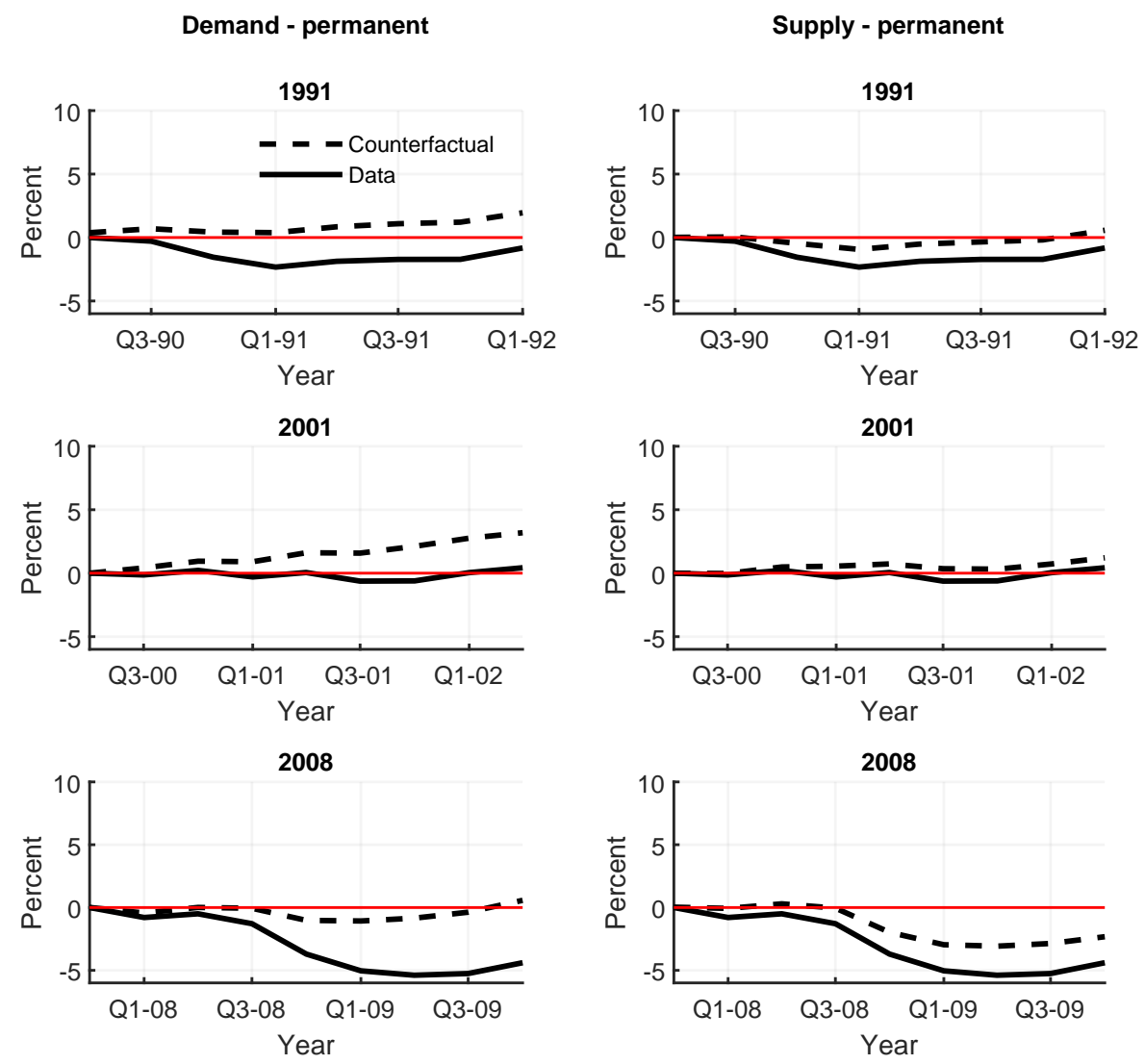


\section{Hysteresis and Jobless Recoveries}

In this section, we examine the sensitivity of our results to the sample under consideration. One obvious question of interest is whether the presence of the Great Recession, by far the largest recession in our data, is driving our results. To check this conjecture, we repeat our analysis over the period 1983:Q1-2007:Q4. The first row of Figure 5 shows the FEVD and the IRFs of output to permanent demand and supply shocks for this sample. Clearly, the role of permanent demand shocks is lower in this period but still not negligible. The IRFs show that the response of output to permanent demand shocks is marginally weaker than the one reported in Figure 1 and the FEVD shows that the weight of permanent demand shocks diminishes when compared with the results in Figure 2. Hence, and not surprisingly, our model seems to suggest particularly strong hysteresis effects associated with the Great Recession. However, evidence of hysteresis is still present during the period associated with the Great Moderation.

Given that our IRFs and FEVD in Section 3 show that hysteresis propagates mainly through employment, it seems natural to expect that the role of permanent demand shocks remains large as long as "jobless" recoveries are included in the sample. To check this conjecture, in a second experiment, we estimate our model over the sample 1949:Q1 - 1982:Q4, a period in which recoveries were not jobless, as discussed in Jaimovich and Siu (2020). We see from the second row of Figure 5 that results are substantially different in this case. The independence assumption describes the data relatively well. The FEVD indicates that permanent demand shocks now play a minor role and the IRFs show that there is no hysteresis; the point-wise median IRF of output to a permanent demand shock converges back to zero. This result is particularly important because it confirms that hysteresis is allowed for but not imposed in our set-up. Hysteresis effects seem to be present in U.S. data only in the more recent period, where jobless recoveries are present. The outcome of this experiment confirms previous evidence from Coibion et al. (2013), who document a clear increase in unemployment persistence in the post-1990 recessions with respect to pre-1990 recessions. In particular, these authors find a rise in long-term unemployment and a change in the cyclicality of disability claims, among other factors.

In a third experiment, we estimate our model over 1954:Q1 - 2019:Q4, a period also considered by Benati and Lubik (2021) in a related study. The results are shown in the third row of Figure 5. Perhaps not surprisingly given the results reported above, we find limited, but not negligible, evidence for hysteresis effects in this sample. In particular, unlike in the second experiment, the point-wise median IRF of output to permanent demand shocks does not converge back to zero after 40 quarters, although the credible set contains zeros at long horizons. The FEVD shows that in the long run most of the unexpected variation in output is explained by permanent supply shocks. Hence, somewhat in line with Benati and Lubik (2021), the posterior probability that hysteresis effects are in fact present over the period 1954:Q1 - 2019:Q4 is lower than in our sample, although not zero. 
Figure 5: IRFs and FEVD for output in alternative samples
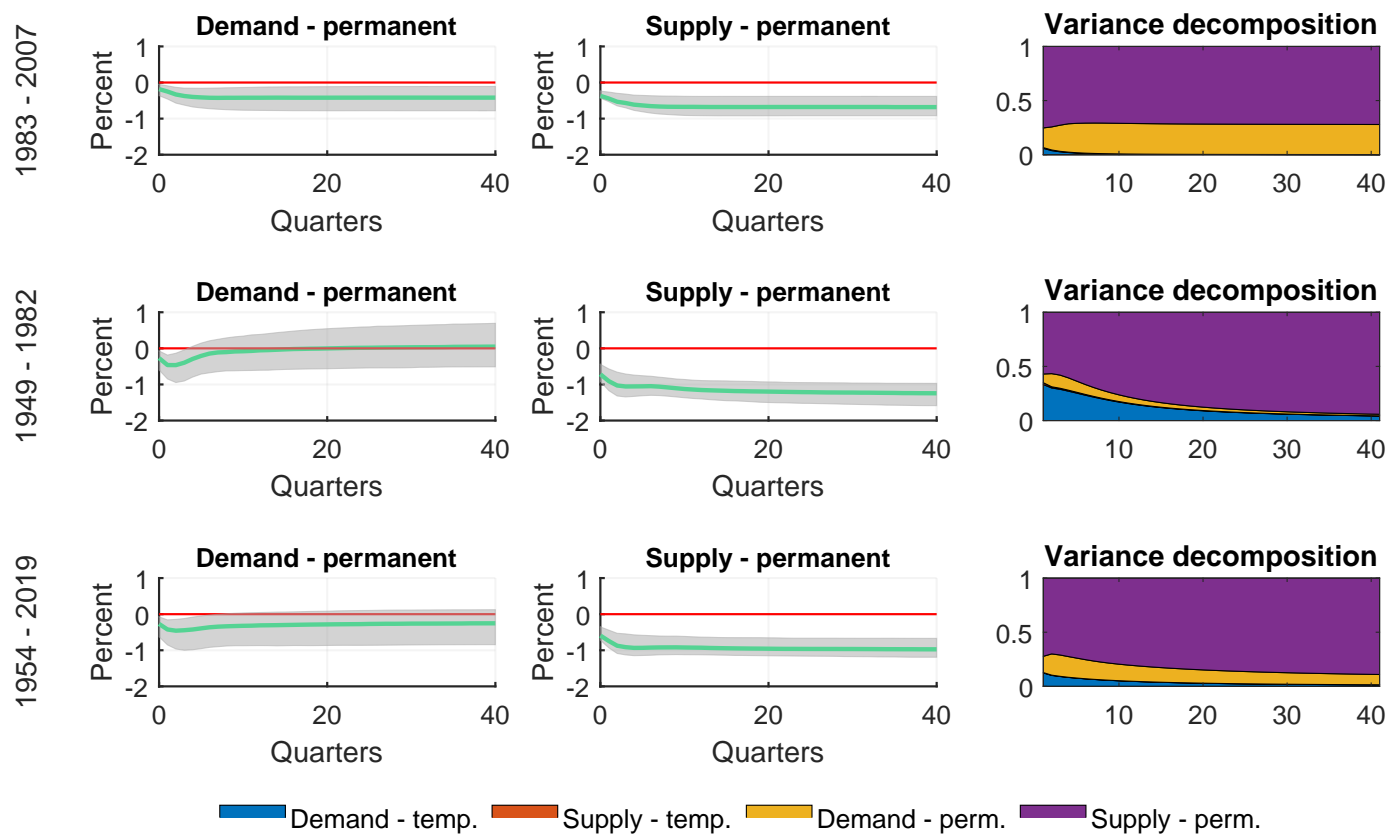

All in all, we find evidence of strong hysteresis effects but only over the last 30 years. This period coincides with the emergence of jobless recoveries. If one extends the sample back to the 1950s, hysteresis survives, although it is quite weaker.

\section{$5 \quad$ Understanding Hysteresis}

We have documented that permanent demand shocks propagate almost entirely through employment, while they have a small effect on output per worker. We now investigate the more granular transmission channels of hysteresis by comparing the responses of other macroeconomic variables related to employment and output per worker to permanent demand shocks. First, we aim to understand why hysteresis transmits through employment. Second, we will try to explain why permanent demand shocks leave output per worker almost unaffected in the long run. We use local projection (LP) methods to analyze the transmission mechanism. The LP approach was proposed by Jordà (2005) and further developed by Ramey and Zubairy (2018), Stock and Watson (2018), and Plagborg-Møller and Wolf (2021), among others. In our particular case, we follow Romer and Romer (2004) and Coibion et al. (2018) and regress each additional variable of interest on current and past values of permanent demand shocks as recovered in our model. One could possibly argue that the additional variable of interest could be added to the VAR. This approach will increment the number of parameters to be estimated and the uncertainty surrounding the IRFs. As argued by Montiel Olea and Plagborg-Møller (2021), once the shocks of in- 
terest are obtained, LP inference is arguably both simpler and more robust than standard autoregressive inference, whose validity is known to be sensitive to the persistence of the data and to the length of the horizon. Accordingly we consider the following regression:

$$
\Delta \mathbf{y}_{t}=\boldsymbol{\alpha}+\sum_{s=1}^{3} \boldsymbol{\lambda}_{s} \Delta \mathbf{y}_{t-s}+\sum_{s=0}^{20} \boldsymbol{\beta}_{s} \mathbf{S}_{t-s}+\boldsymbol{\varepsilon}_{t}
$$

where $\mathbf{y}_{t}$ is the macroeconomic variable of interest and $\mathbf{S}_{t}$ represents the time series for the shock. We use the autoregressive distributed lag specification to estimate IRFs as done by Romer and Romer (2004). Because LP is less efficient than SVARs, we plot IRFs only up to horizon 20. In some cases, we conduct the same regression to trace the effects of permanent supply shocks for comparison. We follow a Bayesian approach whereby for each draw of the shock's distribution, we compute IRFs from Equation (1) using a noninformative normal-Wishart prior on the coefficients. The underlying idea is to calculate the IRFs of a large set of variables conditional on the distribution of shocks. ${ }^{6}$

\subsection{Effects on Employment}

Section 3 finds that hysteresis transmits mostly through employment. In order to understand the channels of the propagation of hysteresis, Figure 6 shows the IRFs of five variables related to employment (the unemployment rate, the fraction of long-term unemployed, the participation rate, as well as applications and awards for disability insurance) to both permanent demand and supply shocks. These five variables are listed by Blanchard (2018) as the leading candidates to be considered when searching for the transmission channels of hysteresis (see also Coibion et al., 2013). The left column of Figure 6 presents the responses to permanent demand shocks, while the right column plots the responses to permanent supply shocks.

The first obvious candidate is the unemployment rate. The IRF of unemployment to both permanent shocks is shown in the first row of the figure. Not surprisingly, the unemployment rate increases persistently in response to the demand shock, although we also observe a significant and similar response (although weaker) to the permanent supply shock. These responses indicate that the unemployment rate cannot be the main propagation channel of hysteresis. As Blanchard (2018) noted, if some workers become less employable or discouraged after a permanent demand shock, then the unemployment numbers will fail to fully recover the transmission channel of hysteresis. In the second row of Figure 6, we consider the ratio of long-term unemployment (unemployed for 27 weeks or more) to total unemployment: its response to permanent demand shocks is stronger and more persistent than its response to permanent supply shocks. Differences are even more

\footnotetext{
${ }^{6}$ This Bayesian approach is similar to Miranda-Agrippino and Ricco (2020). However, since we include lagged values of the variables of interest in the regression, as recommended by Montiel Olea and Plagborg-Møller (2021), we do not need to do autocorrelation adjustments to the posterior, which simplifies inference.
} 
Figure 6: IRFs to permanent demand and supply shocks on labor market variables
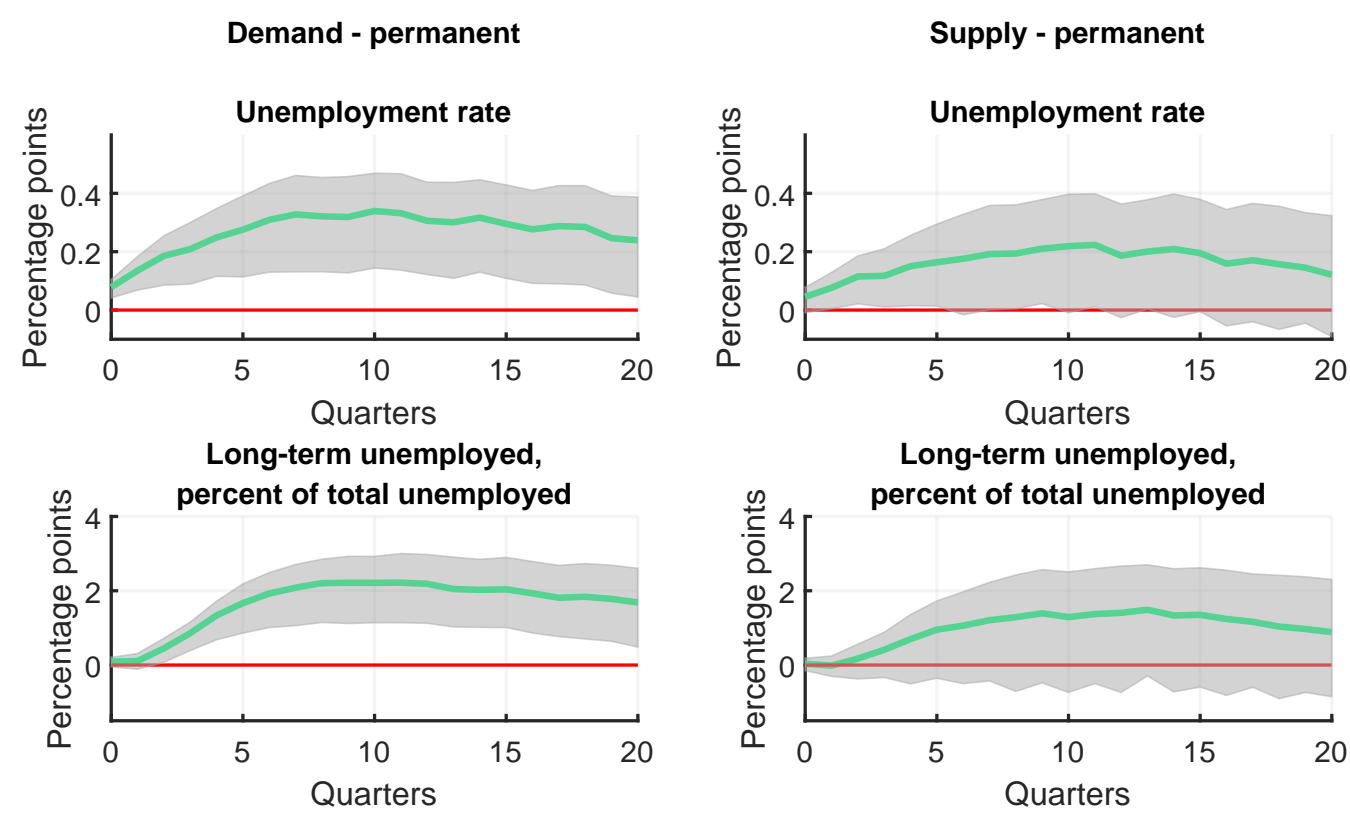

Long-term unemployed,
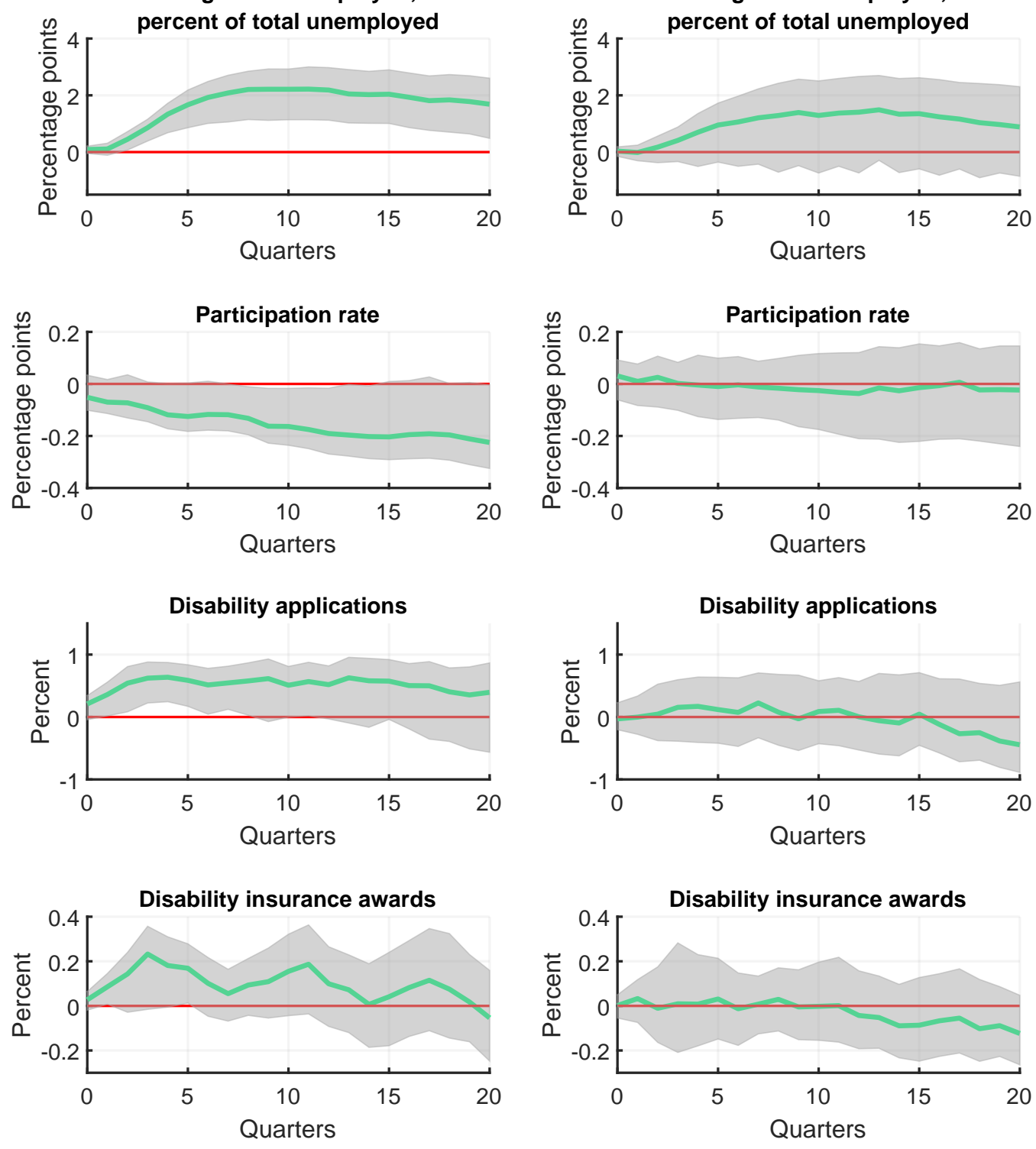
striking when considering the participation rate: we find large and permanent negative effects in response to permanent demand shocks and no effects (on average) in response to permanent supply shocks. This indicates that long-term unemployment and participation rates are important channels of the propagation of hysteresis. Finally, to reinforce the fact that workers became less employable and discouraged after a permanent demand shock, in rows four and five, we consider applications and acceptances for disability insurance. As Blanchard (2018) puts it: "Cyclical variations in applications for disability insurance can give information about the loss of morale among workers as a result of the state of the labor market. And once people are accepted and start receiving disability payments, terminations are rare. This implies that, to the extent that recessions lead to increases in disability insurance rolls, they have a hysteretic effect on the labor force." Our results are consistent with disability insurance rolls having a hysteretic effect on the labor force. The figure shows that while applications and awards respond strongly to demand shocks, they hardly respond at all to supply shocks.

Finally, we would like to stress that the results in Figure 6 also show that the channels of the propagation of hysteresis in recent years are substantially different from the ones discussed in the literature from the 1980s. In particular, Blanchard and Summers (1986) highlighted the role of insiders in wage formation and the potential impact this would have on the unemployment rate. Instead, our results are consistent with studies emphasizing the negative impact of recessions on morale and skills, leading to a rise in long-term unemployment and a decline in the participation rate.

Given that hysteresis transmits through employment, it is of interest to understand how it affects the employment levels of different gender and race groups. To do that we consider more disaggregated data based on gender and race, building on Aaronson et al. (2019). Figure 7 summarizes responses to permanent demand shocks. In the first row, we plot the IRFs of relative employment for black or African American workers, Hispanic and Latino workers, and white American workers. Relative employment is calculated as the deviation of the employment-to-population ratio of a particular group from the aggregate employment-to-population ratio. Clearly, African-American and Hispanic workers are disproportionately affected by permanent demand shocks, while white Americans suffer a lower decline in employment than average. This confirms the results in Aaronson et al. (2019).

In the second and third rows, we consider the responses disaggregated by gender. As before, relative employment for each category is calculated in deviation from the employment-to-population ratio for the whole economy. We note that the employment rate for men falls more in the short run for all races. However, toward the end of the estimation horizon (20 quarters), the effects are roughly similar for men and women, conditional on race. 
Figure 7: IRFs to permanent demand shocks on relative employment by gender and race
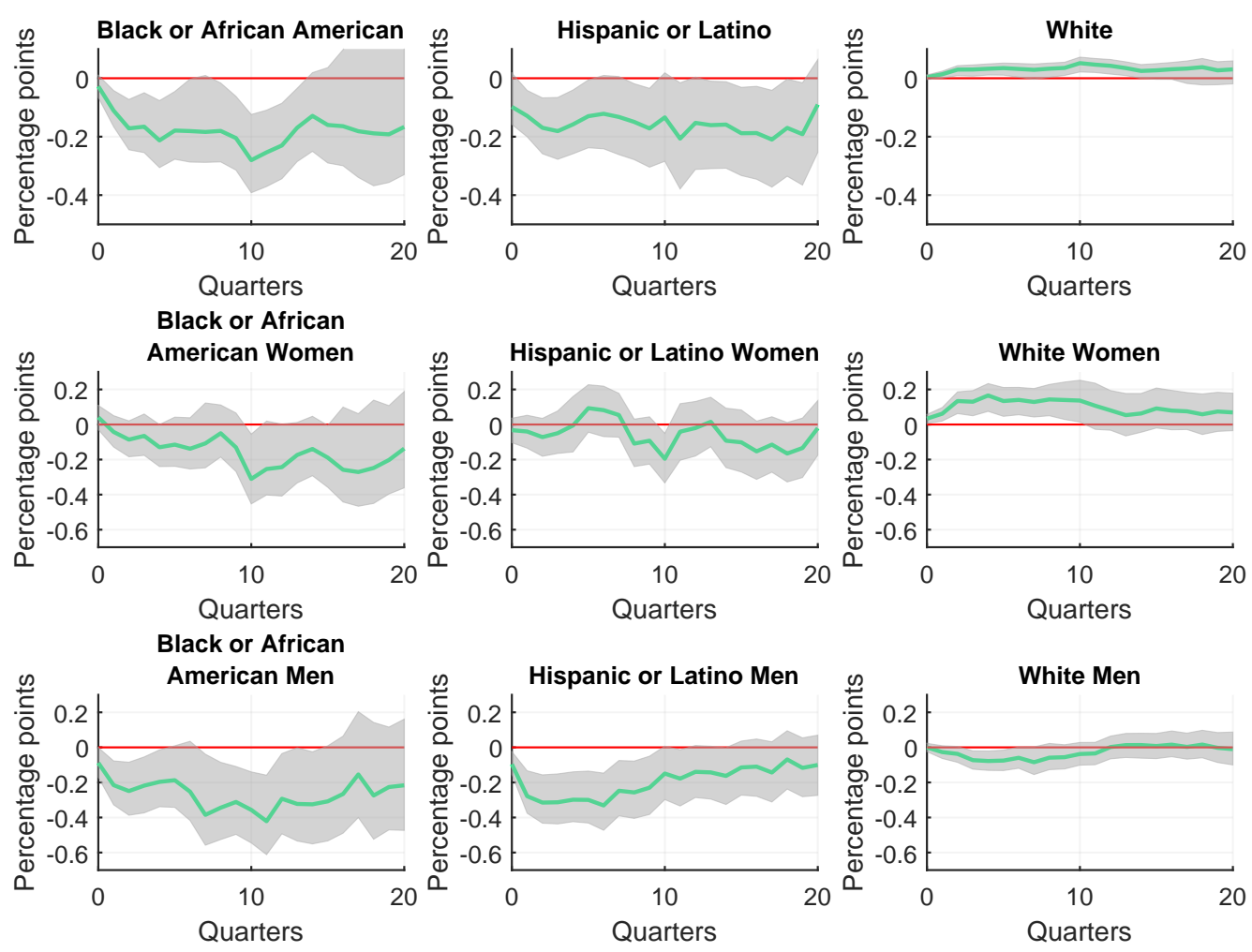

\subsection{Effects on Labor Productivity}

Our results show that strong hysteresis effects on employment are accompanied by limited ones on labor productivity. ${ }^{7}$ At the same time, labor productivity is strongly affected by permanent supply shocks. In order to understand why labor productivity is not a channel of transmission of hysteresis, we decompose labor productivity following the methodology outlined in Fernald (2014). Labor productivity can be written as:

$$
\Delta \ln Y_{t}-\Delta \ln H_{t}=\alpha\left(\Delta \ln K_{t}-\Delta \ln H_{t}\right)+(1-\alpha) \Delta \ln Q_{t}+\Delta \ln U_{t}+\Delta \ln A_{t},
$$

where $Y_{t}$ is output, $H_{t}$ is total hours worked, $K_{t}$ is capital, $Q_{t}$ is labor quality, $U_{t}$ is labor and capital utilization, $A_{t}$ is utilization-adjusted total factor productivity, and $\alpha$ is the share of capital in total output. We use Fernald's up-to-date quarterly estimates of each of these variables to decompose movements in labor productivity into their underlying drivers.

While our measure of labor productivity is output per worker for the whole economy, Fernald's measure of labor productivity is output per hour worked in the U.S. business

\footnotetext{
${ }^{7}$ Similar effects have been uncovered by Bhattarai et al. (2021) for both employment and labor productivity in a more disaggregate analysis at the county level.
} 
Figure 8: IRFs of labor productivity components to permanent demand shocks
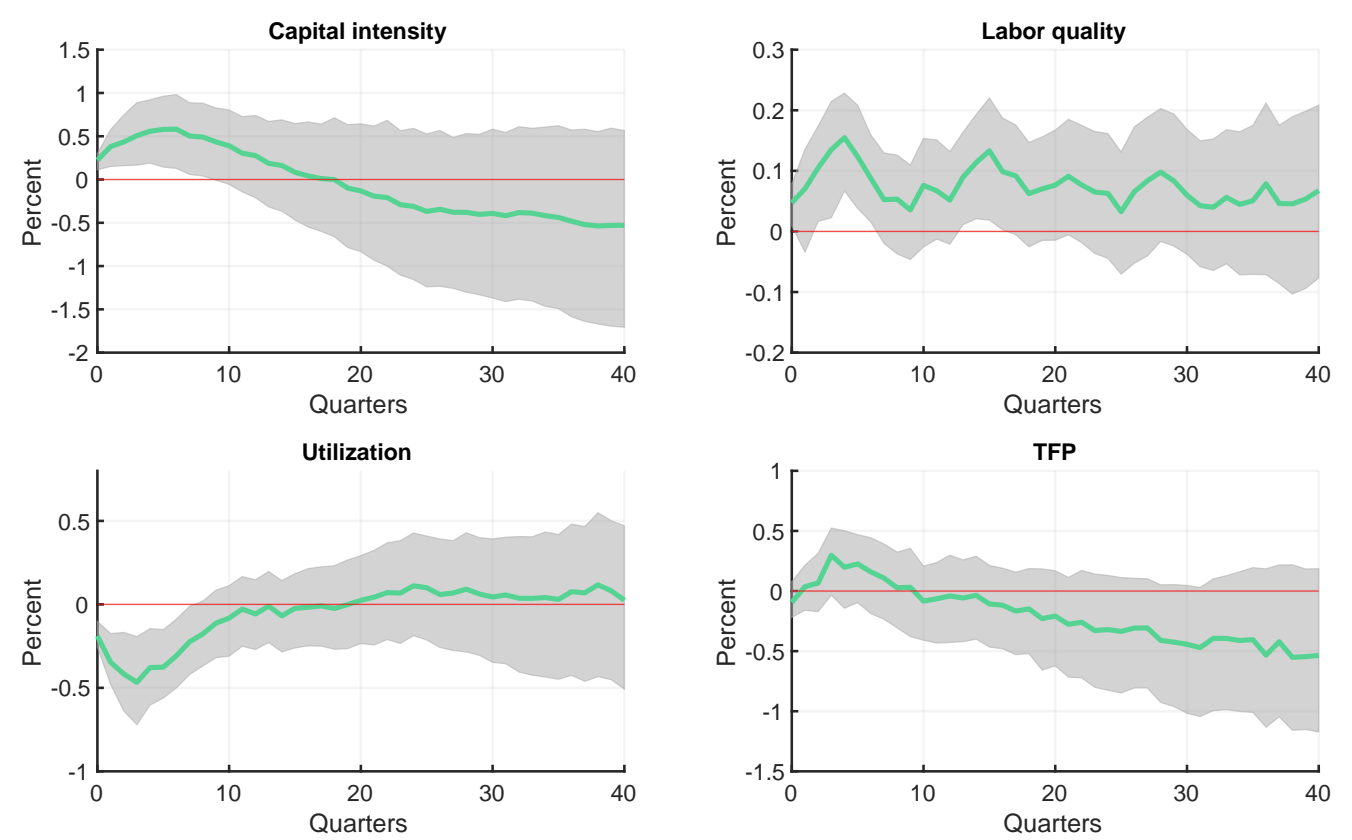

sector. Thus, our first step is to check whether the results reported in Section 3 survive with Fernald's measure of labor productivity. The appendix presents results for the SVAR re-estimated using Fernald's measures of output and hours. Previous results are broadly confirmed, although the uncertainty surrounding the IRFs is larger. As before, we find that labor productivity hardly moves in response to a permanent demand shock.

Next, we use the above decomposition to understand the drivers behind the responses of labor productivity to permanent demand shocks. The panels in Figure 8 plot the IRFs of the different terms on the right-hand side of Equation (2). The IRFs are obtained using the LP approach described above. In this case we show IRFs up to horizon 40 because we want to analyze the long-run effects of permanent demand shocks on TFP.

The figure shows that the muted short-run response of labor productivity to a permanent demand shock is the result of two offsetting effects. On the one hand, capital intensity goes up as employment declines abruptly, while capital reacts only slowly to the decrease in investment. Along with an increase in labor quality and TFP, this tends to push labor productivity up. On the other hand, a large decline in utilization pushes labor productivity down. At longer horizons, TFP turns negative and the protracted slump in investment shown in Figure 1 results in a decrease in capital intensity. These long-run effects are compensated by the improvement in utilization.

A large literature (see Benigno and Fornaro, 2018; Moran and Queralto, 2018; GuerronQuintana and Jinnai, 2019; Ikeda and Kurozumi, 2019; Bianchi et al., 2019; Anzoategui et al., 2019; Garga and Singh, 2021) has developed New Keynesian models with endogenous growth in which demand shocks can have long-lasting effects on output. A key transmission mechanism in this literature is that a contractionary demand shock results in a 
Figure 9: IRFs of selected variables to permanent demand shocks
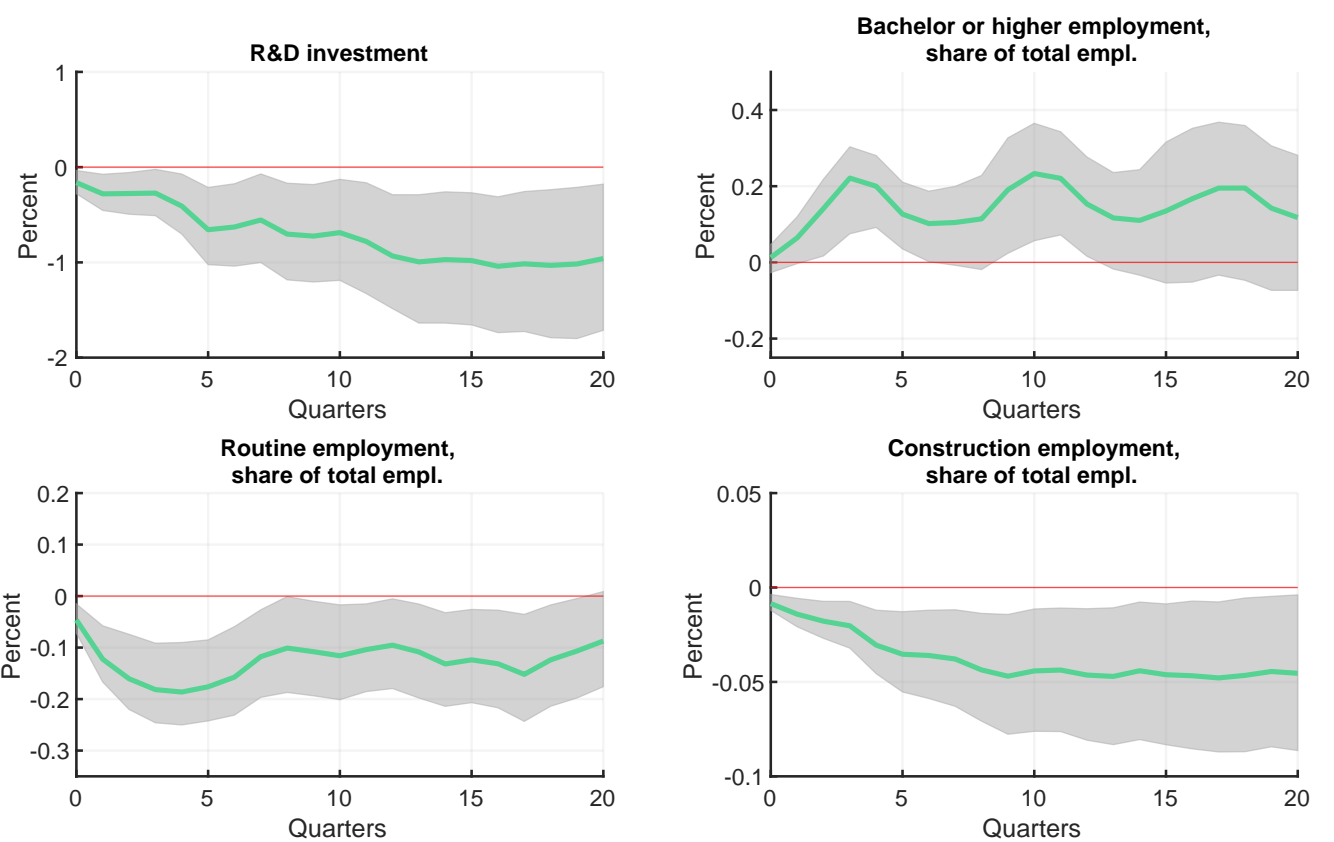

decline in productivity-enhancing investment, notably research and development (R\&D), which later triggers a persistent slowdown in TFP. We find evidence in favor of this channel. The top-left panel of Figure 9 shows that our permanent demand shock leads to a protracted decline in $\mathrm{R} \& \mathrm{D}$ investment. In turn, this decline in R\&D investment could potentially be responsible for the negative response of TFP at long horizons that we observe in Figure 8.

Moreover, the fact that labor quality increases significantly in response to permanent demand shocks suggests that demand-driven recessions are periods of intense restructuring in which the least productive units or workers are disproportionately affected. According to this view, firms grow fat during economic expansions before aggressively restructuring in recessions (Berger, 2012). This leaves them better equipped to serve demand with a smaller workforce in the ensuing expansion, thereby leading to jobless recoveries, in line with our evidence. The top-right panel of Figure 9 validates this interpretation. The employment share for skilled workers increases after a permanent demand shock, which means that employment for skilled workers declines less than for other workers. As an additional piece of evidence, we also consider the routine employment share, defined as the ratio of employment of workers performing routine tasks (as classified in Jaimovich and Siu, 2020) over total employment, on the bottom-left panel of Figure 9. We observe that permanent demand shocks persistently displace workers performing routine tasks. This result is in keeping with the fact that job polarization takes place mainly in recessions and generates jobless recoveries, as shown by Jaimovich and Siu (2020).

It is reasonable to think that similar composition effects are at play also on the firm side, causing less efficient production units to become unprofitable and shut down. Our 
evidence is admittedly weaker in that dimension. However, one fact that is consistent with this narrative is the large and permanent effect of a negative demand shock on employment in the construction sector (see the bottom-right panel of Figure 9). Productivity in the construction sector is notoriously low and thus a shrinking level of economic activity in that sector will lead to an improvement in aggregate productivity.

All in all, we find that the limited effect of permanent demand shocks on labor productivity is the result of offsetting movements in labor and capital utilization, capital intensity, and labor quality. While utilization falls in the short run, both capital intensity and labor quality go up, thus explaining the neutral effect on the aggregate. We also uncover some evidence in favor of theories in which decreases in R\&D investment in (demand-driven) recessions are followed by long-run declines in TFP growth.

\section{Robustness}

In this section, we investigate the robustness of our results along several dimensions. We first analyze the sensitivity of our results to breaks and low-frequency correlations. Second, we look at the role of transitory shocks throughout history. Third, we analyze how the results change when we use the employment level instead of employment growth. Finally, we discuss the possible commingling between permanent demand shocks and sectoral supply shocks.

\subsection{Forecast Error Variance Decomposition Stability}

As shown by Fernald (2007), the FEVD implied by SVAR models identified with long-run restrictions is sensitive to trend breaks and low-frequency correlations. This instability is also discussed in the original paper by Blanchard and Quah (1989), where the share of the forecast error variance of output explained by transitory disturbances ranges from 40 to 95 percent at a forecast horizon of four quarters, depending on how structural breaks or slow-moving trends are treated. The first row of Figure 10 replicates Tables 2 and 2C in the original paper. In the left panel, we do not make any adjustments to the series. As in Blanchard and Quah (1989), in the right panel, we detrend the unemployment series and we impose a break in 1973:Q4 and demean the output growth series in the two sub-samples. The dominant role of the transitory shocks in the short to medium run only emerges when the series are adjusted. In the second row, we report results for the Blanchard-Quah model over our sample period. In the left panel, we do not adjust the series, while in the right panel, we detrend unemployment and impose a break in 2008:Q4 (when output growth slows down significantly) and demean the output growth series in the two sub-samples. While transitory shocks play a minor role when no adjustments are made, they explain more than 50 percent of short-run output fluctuations when we detrend the unemployment rate and demean output growth. Following the same approach, 
Figure 10: Forecast error variance decompositions of output in different models and samples
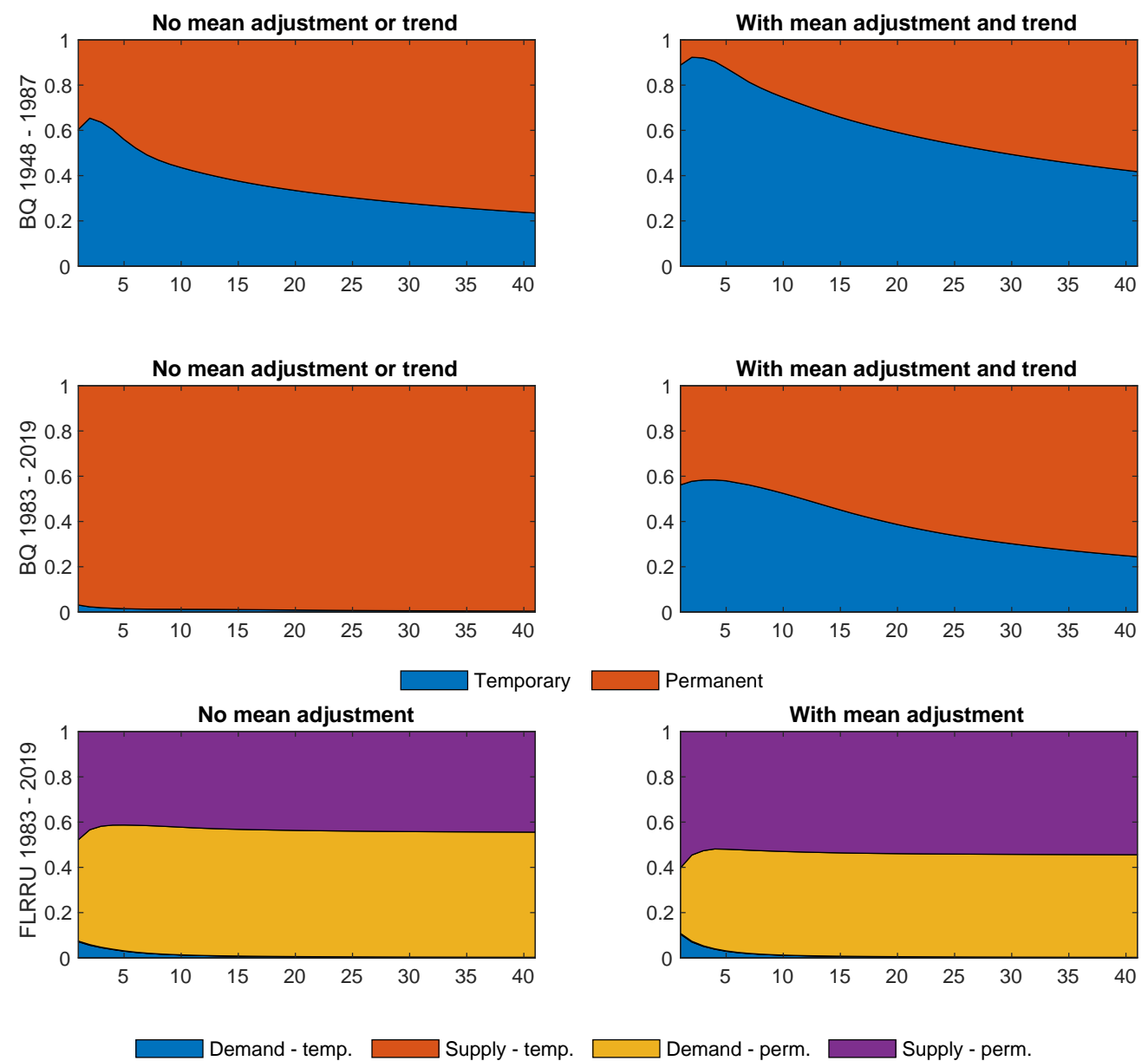

$\square$ Demand - perm.

Supply - perm.

we investigate whether our model suffers the same kind of instability. In the third row of Figure 10, we present the FEVD of output for our model. The left column has no adjustment, while all the series are demeaned (again with a break imposed in 2008:Q4) in the right column. ${ }^{8}$ In contrast with Blanchard and Quah (1989), the adjustment has limited effects on our results, with only a slightly larger role for transitory and permanent supply shocks.

\subsection{Role of Transitory Shocks over History}

Next, we check whether the limited role of transitory shocks is robust to the sample period. To investigate this point, we recursively estimate the model over a 120-quarter rolling window and compute the cumulative FEVD of output and employment for each period. Hence, our first model is estimated over the sample 1953:Q2-1983:Q1, while the

\footnotetext{
${ }^{8}$ Note that employment enters our model in first differences, unlike the unemployment rate in Blanchard and Quah (1989). This implies that we do not need to detrend it to remove its low-frequency component.
} 
last model is estimated over the sample 1990:Q1-2019:Q4. The left column of Figure 11 shows the share of the forecast error variance in output and employment explained by the two transitory shocks after four quarters. Each point in the blue lines corresponds to the share of the forecast error variance obtained in a model estimated over the previous 30 years. Transitory shocks play an important role until the early 2000s, but after that date, their importance diminishes. The right column of Figure 11 shows the share of forecast error variance in output and employment explained by the permanent demand shock after 40 quarters. This shock does not seem to play a relevant role at the beginning of the sample and it only becomes important in the current century. These results confirm the critical role of hysteresis in recessions associated with jobless recoveries in general, and the Great Recession in particular.

Figure 11: Rolling window estimation (120-quarter window)

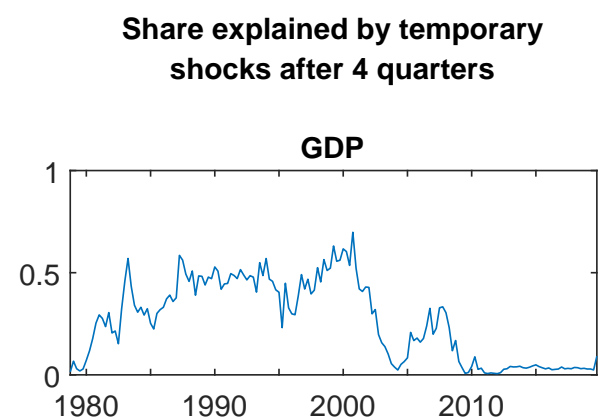
Share explained by permanent demand
shocks after 40 quarters
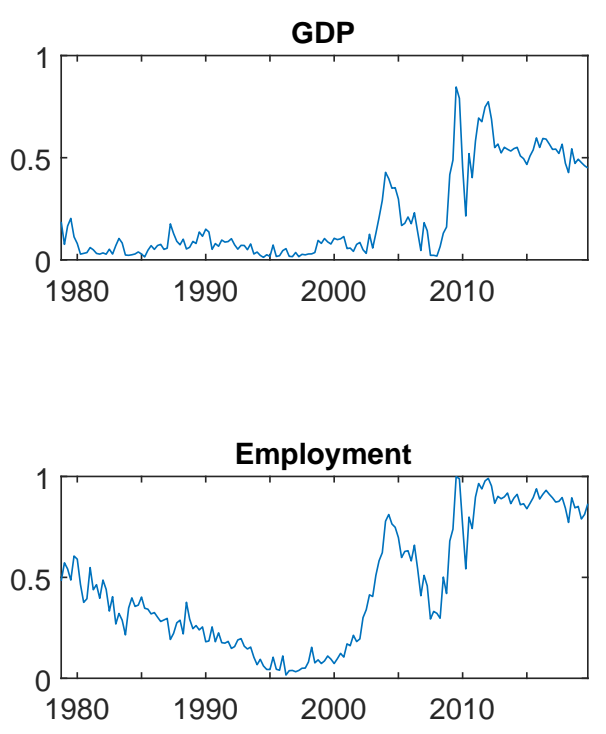

\subsection{Employment Data in Levels}

In section 3 we used employment growth in our SVAR. Since Blanchard and Quah (1989) use unemployment and not unemployment growth, we now check the robustness of our results to including the employment level instead. In this case, all shocks have a transitory effect on employment as long as the system is stationary. The IRFs of output and employment after the two permanent shocks and FEVD of output for this exercise are shown in Figure 12. As expected, while both shocks have permanent effects on output, none of the shocks have a permanent effect on employment, although they are quite persistent. It is still the case that the permanent demand shock explains a significant share of the forecast error variance of output at a 40-quarter horizon. Thus, these results show that 
Figure 12: IRFs and forecast error variance decomposition

(Model with employment-to-population ratio in level)
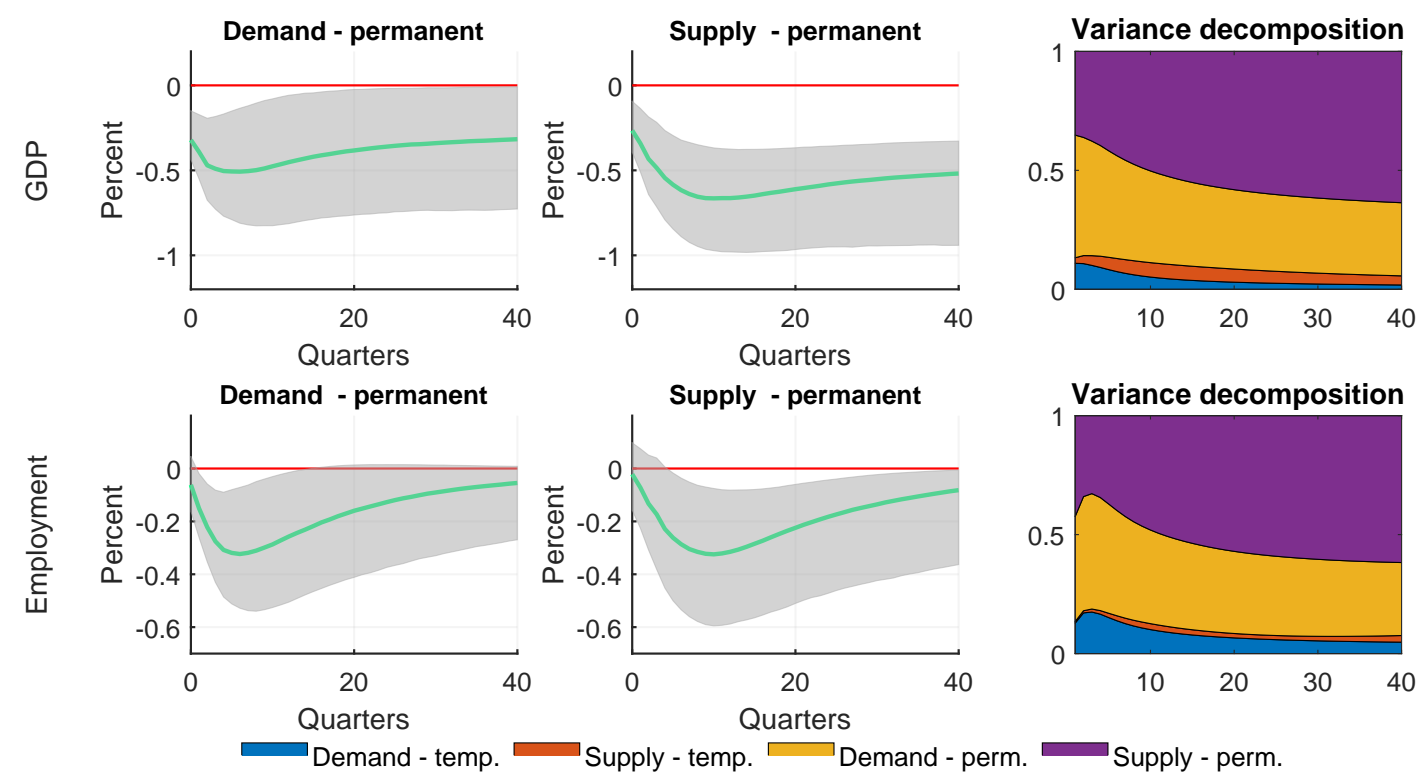

considering employment growth is not crucial to finding hysteresis.

\subsection{Commingling with Sectoral Shocks}

One may wonder whether the identified permanent demand shock is contaminated by sectoral supply shocks. Theoretically, these shocks may lead to a positive co-movement between output growth and inflation in the aggregate in the presence of strong complementarities across sectors, as in Guerrieri et al. (2020). Thus, in principle, it is possible that our identification scheme labels these so-called "Keynesian" supply shocks as demand shocks. However, we think that there are at least two reasons to believe that Keynesian supply shocks are not important drivers of our identified permanent demand shock. First, these shocks are assumed to be transitory by Guerrieri et al. (2020), while our results show that permanent demand shocks (not transitory ones) are the important drivers of fluctuations in output and employment. Thus, to the extent that Keynesian supply shocks are captured in our analysis, they should be bundled up with transitory demand shocks, which have limited effects on real variables. Second, Baqaee and Farhi (2020) show that transitory sectoral supply shocks generate negative co-movement between output and inflation once input-output linkages are properly taken into account. ${ }^{9}$

There are other kinds of sectoral supply shocks that may generate permanent effects,

\footnotetext{
${ }^{9}$ Fornaro and Wolf (2020) show that aggregate supply shocks can also generate Keynesian effects under specific parameterizations in a Keynesian growth framework. However, these shocks propagate mainly through labor productivity, unlike our permanent demand shocks. For empirical evidence on the effects of Keynesian supply shocks, see Cesa Bianchi and Ferrero (2020).
} 
Figure 13: Forecast error variance decomposition

(Model with the relative price of investment as an observable)

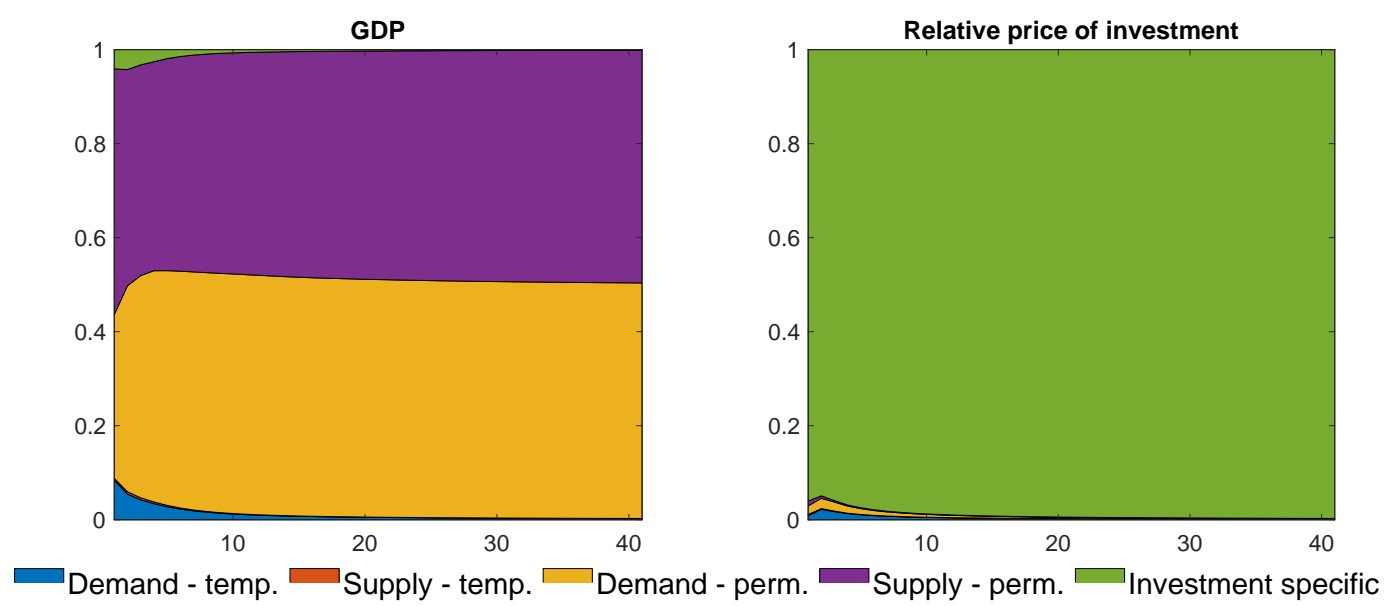

with the most natural candidates being shocks to the investment-specific technology. Therefore, we extend our model by including the relative price of investment as an observable. Following Fisher (2006), we identify an investment-specific technology shock as the only shock having a long-run effect on the relative price of investment. We also impose the innocuous assumption that the shock generates a negative co-movement between output (and investment) and the relative price of investment, while leaving inflation unrestricted. As shown in Figure 13, investment-specific shocks play a limited role in the model (except obviously for the relative price of investment) and permanent demand shocks retain an important explanatory power.

\section{Conclusion}

In this paper we have challenged the independence assumption embedded in macroeconomic analysis. This assumption implies that output can be decomposed into a trend, in which surprises are driven only by supply shocks, and transitory fluctuations around the trend, mostly driven by demand shocks. We have shown that demand shocks may generate hysteresis effects. Recessions (and booms) driven by demand shocks may have permanent effects on potential output and employment. In particular, our results have shown that permanent demand shocks explain a significant share of the decline in employment in the aftermath of the Great Recession. Hysteresis effects transmit through employment but do not affect output per worker. While our paper is purely empirical and does not provide normative implications, we believe it is important to have sound empirical evidence on the relevance of hysteresis effects to inform the policy discussion (cf. Galí, 2020; Garga and Singh, 2021).

It is also worth stressing that our simple analysis is only a first step toward estimat- 
ing hysteresis effects. As shown by Benigno et al. (2015), non-linearities are potentially important in studying unemployment, labor productivity and their drivers. Introducing non-linearities in our set-up is certainly promising and desirable, although far from trivial insofar as the literature has not reached a consensus on how to integrate sign restrictions into non-linear models.

Another avenue for future research consists of disentangling further the origin of hysteresis effects. Bianchi et al. (2019) and Guerron-Quintana and Jinnai (2019) find an important role for shocks related to investment (shocks to the marginal efficiency of investment and liquidity shocks, respectively), while supporting evidence on the long-run effects of monetary and fiscal shocks is provided in Jordà et al. (2020) and Fatás and Summers (2018). Fernández-Villaverde et al. (2019) document the long-lasting effects of discount factor shocks in the presence of search complementarities. All of these shocks are bundled together in our analysis, and disentangling the different components would be worthwhile at the cost, however, of compromising the simplicity of our approach. 


\section{References}

Aaronson, S., Daly, M., Wascher, W., and Wilcox, D. (2019). Okun revisited: Who benefits most from a strong economy? Brookings Papers on Economic Activity, 2019:333-404.

Altig, D., Christiano, L., Eichenbaum, M., and Linde, J. (2011). Firm-specific capital, nominal rigidities and the business cycle. Review of Economic Dynamics, 14(2):225-247.

Angeletos, G.-M., Collard, F., and Dellas, H. (2020). Business cycle anatomy. American Economic Review, 110(10):3030-3070.

Antolin-Diaz, J., Drechsel, T., and Petrella, I. (2017). Tracking the slowdown in long-run GDP growth. Review of Economics and Statistics, 99(2):343-356.

Anzoategui, D., Comin, D., Gertler, M., and Martinez, J. (2019). Endogenous technology adoption and $\mathrm{R} \& \mathrm{D}$ as sources of business cycle persistence. American Economic Journal: Macroeconomics, 11(3):67-110.

Arias, J., Rubio-Ramirez, J., and Waggoner, D. (2018). Inference based on structural vector autoregressions identified with sign and zero restrictions: Theory and applications. Econometrica, 86(2):685-720.

Ball, L. (2014). Long-term damage from the Great Recession in OECD countries. European Journal of Economics and Economic Policies: Intervention, 11(2):149-160.

Ball, L., Mankiw, G., and Nordhaus, W. (1999). Aggregate demand and long-run unemployment. Brookings Papers on Economic Activity, 1999(2):189-251.

Baqaee, D. and Farhi, E. (2020). Supply and demand in disaggregated Keynesian economies with an application to the covid-19 crisis. CEPR Discussion Papers 14743.

Basu, S., Fernald, J., and Kimball, M. (2006). Are technology improvements contractionary? American Economic Review, 96(5):1418-1448.

Benati, L. and Lubik, T. (2021). Searching for hysteresis. Federal Reserve Bank of Richmond Working Paper 21-03.

Benigno, G. and Fornaro, L. (2018). Stagnation traps. Review of Economic Studies, 85(3):1425-1470.

Benigno, P., Ricci, L. A., and Surico, P. (2015). Unemployment and productivity in the long run: the role of macroeconomic volatility. Review of Economics and Statistics, 97(3):698-709.

Berger, D. (2012). Countercyclical restructuring and jobless recoveries. 2012 Meeting Papers 1179, Society for Economic Dynamics. 
Bhattarai, S., Schwartzman, F., and Yang, C. (2021). Local scars of the us housing crisis. Journal of Monetary Economics, 119:40-57.

Bianchi, F., Kung, H., and Morales, G. (2019). Growth, slowdowns, and recoveries. Journal of Monetary Economics, 101:47-63.

Blanchard, O. (2018). Should we reject the natural rate hypothesis? Journal of Economic Perspectives, 32(1):97-120.

Blanchard, O., Cerutti, E., and Summers, L. (2015). Inflation and activity-two explorations and their monetary policy implications. NBER Working Paper 21726.

Blanchard, O. and Quah, D. (1989). The dynamic effects of aggregate demand and aggregate supply. American Economic Review, 79(4):655-673.

Blanchard, O. and Summers, L. (1986). Hysteresis and the European unemployment problem. NBER Macroeconomics Annual, 1:15-78.

Bluedorn, J. and Leigh, D. (2019). Hysteresis in labor markets? Evidence from professional long-term forecasts. Working Paper 19/114, International Monetary Fund.

Canova, F. and De Nicoló, G. (2002). Monetary disturbances matter for business fluctuations in the G-7. Journal of Monetary Economics, 49(6):1131-1159.

Canova, F. and Paustian, M. (2011). Business cycle measurement with some theory. Journal of Monetary Economics, 58(4):345-361.

Cerra, V., Fatás, A., and Saxena, S. (2020). Hysteresis and business cycles. CEPR Discussion Paper 14531.

Cerra, V. and Saxena, S. (2008). Growth dynamics: the myth of economic recovery. American Economic Review, 98(1):439-57.

Cesa Bianchi, A. and Ferrero, A. (2020). The transmission of Keynesian supply shocks. Manuscript.

Christiano, L. J., Eichenbaum, M., and Vigfusson, R. (2003). What happens after a technology shock? NBER Working Paper 9819.

Coibion, O., Gorodnichenko, Y., and Koustas, D. (2013). Amerisclerosis? The puzzle of rising US unemployment persistence. Brookings Papers on Economic Activity, 2013(2):193-260.

Coibion, O., Gorodnichenko, Y., and Ulate, M. (2018). The cyclical sensitivity in estimates of potential output. Brookings Papers on Economic Activity, pages 343-441. 
Del Negro, M., Lenza, M., Primiceri, G., and Tambalotti, A. (2020). What's up with the Phillips curve? Brooking Papers on Economic Activity Conference Draft, Spring.

Doan, T., Litterman, R., and Sims, C. (1984). Forecasting and conditional projection using realistic prior distributions. Econometric Reviews, 3(1):1-100.

Dolado, J. and Jimeno, J. F. (1997). The causes of Spanish unemployment: A structural VAR approach. European Economic Review, 41(7):1281-1307.

Dosi, G., Pereira, M. C., Roventini, A., and Virgillito, M. E. (2018). Causes and consequences of hysteresis: aggregate demand, productivity, and employment. Industrial and Corporate Change, 27(6):1015-1044.

Dupraz, S., Nakamura, E., and Steinsson, J. (2019). A plucking model of business cycles. NBER Working Paper 26351.

Eo, Y. and Morley, J. (2020). Why has the US economy stagnated since the Great Recession? Review of Economics and Statistics, forthcoming.

Fatás, A. and Summers, L. (2018). The permanent effects of fiscal consolidations. Journal of International Economics, 112:238-250.

Faust, J. (1998). The robustness of identified VAR conclusions about money. CarnegieRochester Conference Series on Public Policy, 49:207-244.

Fernald, J. (2007). Trend breaks, long-run restrictions, and contractionary technology improvements. Journal of Monetary Economics, 54(8):2467-2485.

Fernald, J. (2014). A quarterly, utilization-adjusted series on total factor productivity. Working Paper 2012-19, Federal Reserve Bank of San Francisco.

Fernald, J., Stock, J., Hall, R., and Watson, M. (2017). The disappointing recovery of output after 2009. Brookings Papers on Economic Activity, 48:1-58.

Fernández-Villaverde, J., Mandelman, F., Yu, Y., and Zanetti, F. (2019). Search complementarities, aggregate fluctuations, and fiscal policy. NBER Working Paper 26210.

Fisher, J. D. (2006). The dynamic effects of neutral and investment-specific technology shocks. Journal of Political Economy, 114(3):413-451.

Fornaro, L. and Wolf, M. (2020). The scars of supply shocks. CEPR Discussion Paper 15423.

Galí, J. (1999). Technology, employment, and the business cycle: do technology shocks explain aggregate fluctuations? American Economic Review, 89(1):249-271. 
Galí, J. (2020). Insider-outsider labor markets, hysteresis and monetary policy. Journal of Money Credit and Banking, forthcoming.

Galí, J. and Hammour, M. (1992). Long run effects of business cycles. Working Paper Columbia - Graduate School of Business.

Galí, J., López-Salido, D., and Vallés, J. (2003). Technology shocks and monetary policy: assessing the Fed's performance. Journal of Monetary Economics, 50(4):723-743.

Galí, J. and Rabanal, P. (2004). Technology shocks and aggregate fluctuations: How well does the real business cycle model fit postwar us data? NBER Macroeconomics Annual, 19:225-288.

Gambetti, L. and Pistoresi, B. (2004). Policy matters. the long run effects of aggregate demand and mark-up shocks on the Italian unemployment rate. Empirical Economics, 29(2):209-226.

Garga, V. and Singh, S. (2021). Output hysteresis and optimal monetary policy. Journal of Monetary Economics, 117:871-886.

Giannone, D., Lenza, M., and Primiceri, G. E. (2015). Prior selection for vector autoregressions. Review of Economics and Statistics, 97(2):436-451.

Gordon, R. (2015). Secular stagnation: A supply-side view. American Economic Review, 105(5):54-59.

Guerrieri, V., Lorenzoni, G., Straub, L., and Werning, I. (2020). Macroeconomic implications of covid-19: Can negative supply shocks cause demand shortages? NBER Working Paper 26918.

Guerron-Quintana, P. and Jinnai, R. (2019). Financial frictions, trends, and the Great Recession. Quantitative Economics, 10(2):735-773.

Ikeda, D. and Kurozumi, T. (2019). Slow post-financial crisis recovery and monetary policy. American Economic Journal: Macroeconomics, 11(4):82-112.

Jacobson, T., Vredin, A., and Warne, A. (1997). Common trends and hysteresis in Scandinavian unemployment. European Economic Review, 41(9):1781-1816.

Jaimovich, N. and Siu, H. (2020). Job polarization and jobless recoveries. Review of Economics and Statistics, 102(1):129-147.

Jordà, Ò. (2005). Estimation and Inference of Impulse Responses by Local Projections. American Economic Review, 95(1):161-182. 
Jordà, Ò., Singh, S., and Taylor, A. (2020). The long-run effects of monetary policy. Working Paper 2020-09, Federal Reserve Bank of San Francisco.

Kozlowski, J., Veldkamp, L., and Venkateswaran, V. (2020). The tail that wags the economy: Beliefs and persistent stagnation. Journal of Political Economy, 128(8):28392879 .

Maffei Faccioli, N. (2020). Identifying the sources of the economic slowdown: demand vs supply. Job Market Paper.

Mertens, K. and Ravn, M. (2011). Technology-hours redux: Tax changes and the measurement of technology shocks. NBER International Seminar on Macroeconomics, 7(1):4176.

Miranda-Agrippino, S. and Ricco, G. (2020). The transmission of monetary policy shocks. American Economic Journal: Macroeconomics, forthcoming.

Montiel Olea, J. L. and Plagborg-Møller, M. (2021). Local projection inference is simpler and more robust than you think. Econometrica, forthcoming.

Moran, P. and Queralto, A. (2018). Innovation, productivity, and monetary policy. Journal of Monetary Economics, 93:24-41.

Paciello, L. (2011). Does inflation adjust faster to aggregate technology shocks than to monetary policy shocks? Journal of Money, Credit and Banking, 43(8):1663-1684.

Plagborg-Møller, M. and Wolf, C. K. (2021). Local Projections and VARs Estimate the Same Impulse Responses. Econometrica, forthcoming.

Ramey, V. A. and Zubairy, S. (2018). Government Spending Multipliers in Good Times and in Bad: Evidence from US Historical Data. Journal of Political Economy, 126(2):850-901.

Romer, C. and Romer, D. (2004). A new measure of monetary shocks: Derivation and implications. American Economic Review, 94(4):1055-1084.

Rubio-Ramirez, J., Waggoner, D., and Zha, T. (2010). Structural vector autoregressions: Theory of identification and algorithms for inference. Review of Economic Studies, $77(2): 665-696$.

Stock, J. H. and Watson, M. W. (2018). Identification and Estimation of Dynamic Causal Effects in Macroeconomics Using External Instruments. The Economic Journal, 128(610):917-948.

Summers, L. (2014). Fiscal policy and full employment. Speech at Center on Budget and Policy Priorities Event on Full Employment. 
Summers, L. (2015). Demand side secular stagnation. American Economic Review, $105(5): 60-65$.

Uhlig, H. (2005). What are the effects of monetary policy on output? Results from an agnostic identification procedure. Journal of Monetary Economics, 52(2):381-419.

Yagan, D. (2019). Employment hysteresis from the Great Recession. Journal of Political Economy, 127(5):2505-2558. 


\section{For Online Publication: Appendix}

In Figure A-1 we replicate the results in Blanchard and Quah (1989), using the algorithm proposed by Arias et al. (2018) in terms of IRFs and variance decompositions. Figure A-2 presents IRFs to the two transitory shocks. Figures A-3 and A-4 present the IRFs and the FEVD when we re-estimated the SVAR using Fernald's measure of output and hours. Figure A-5 presents results for a version of the model in which all sign restrictions are imposed at horizon four rather than on impact.

Figure A-1: Replication of Blanchard and Quah
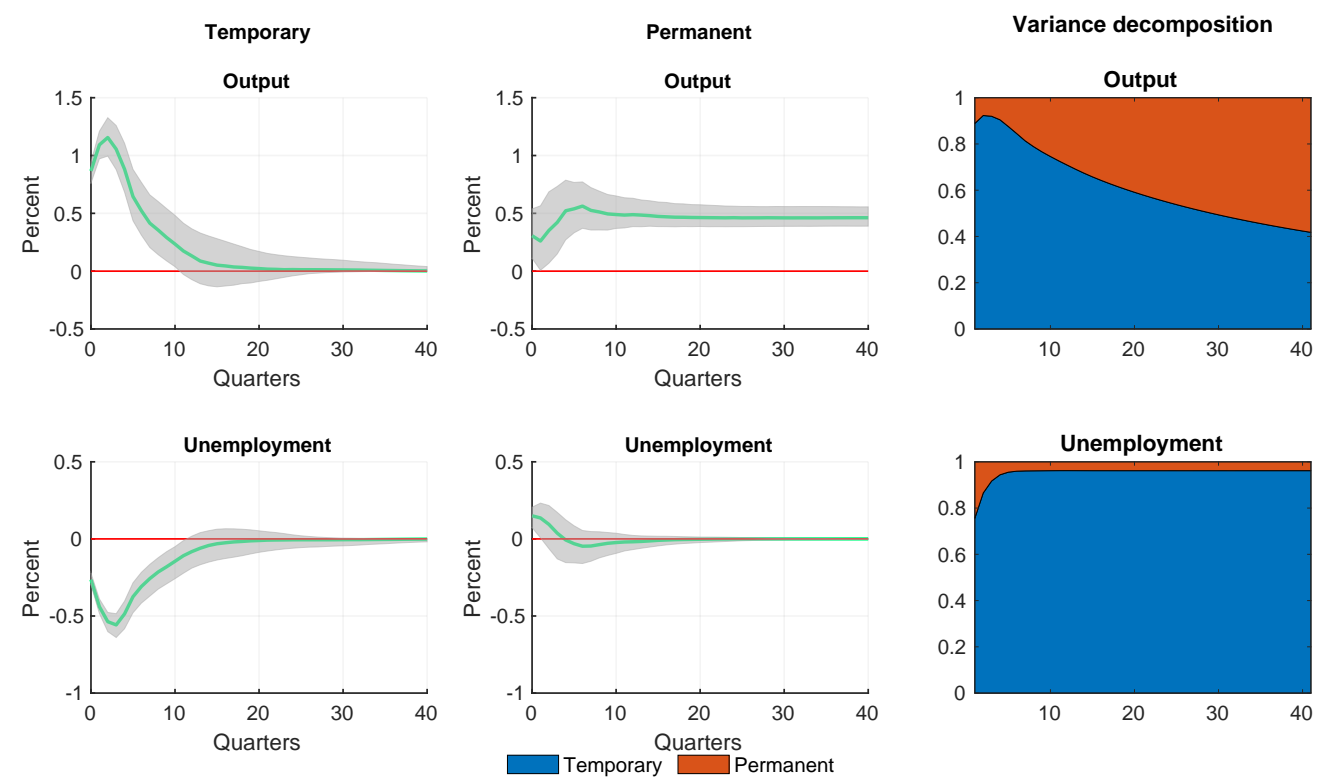
Figure A-2: IRFs to transitory demand and supply shocks

Demand - temporary

GDP
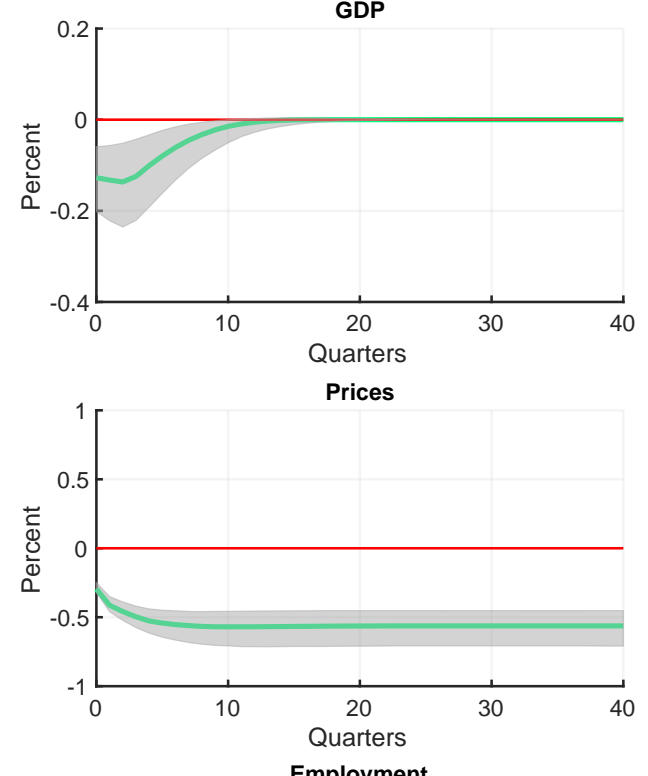

Employment

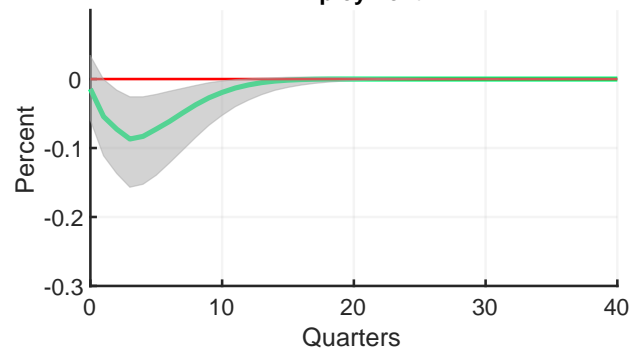

Output per worker
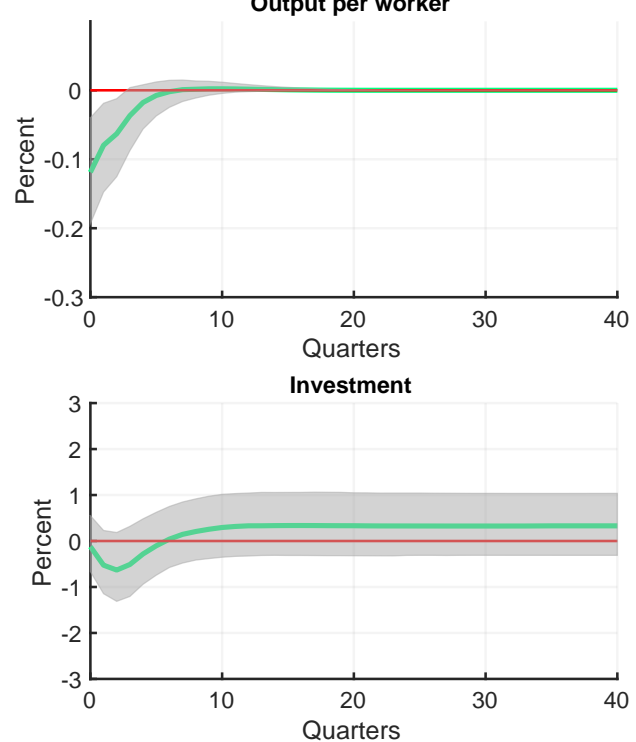

Supply - temporary

GDP
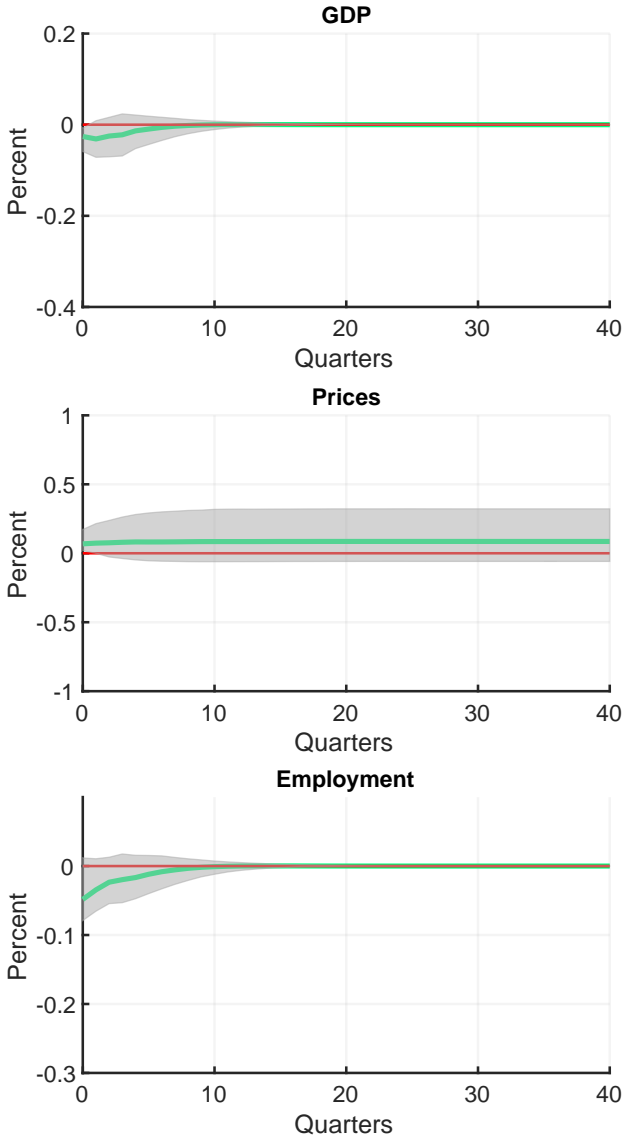

Output per worker
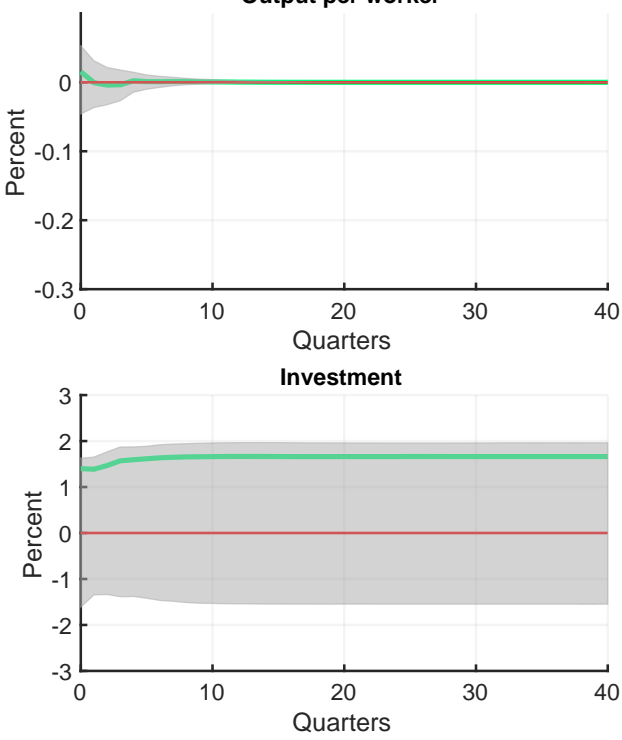
Figure A-3: IRFs to the permanent demand and supply shock (Using business sector output and hours)
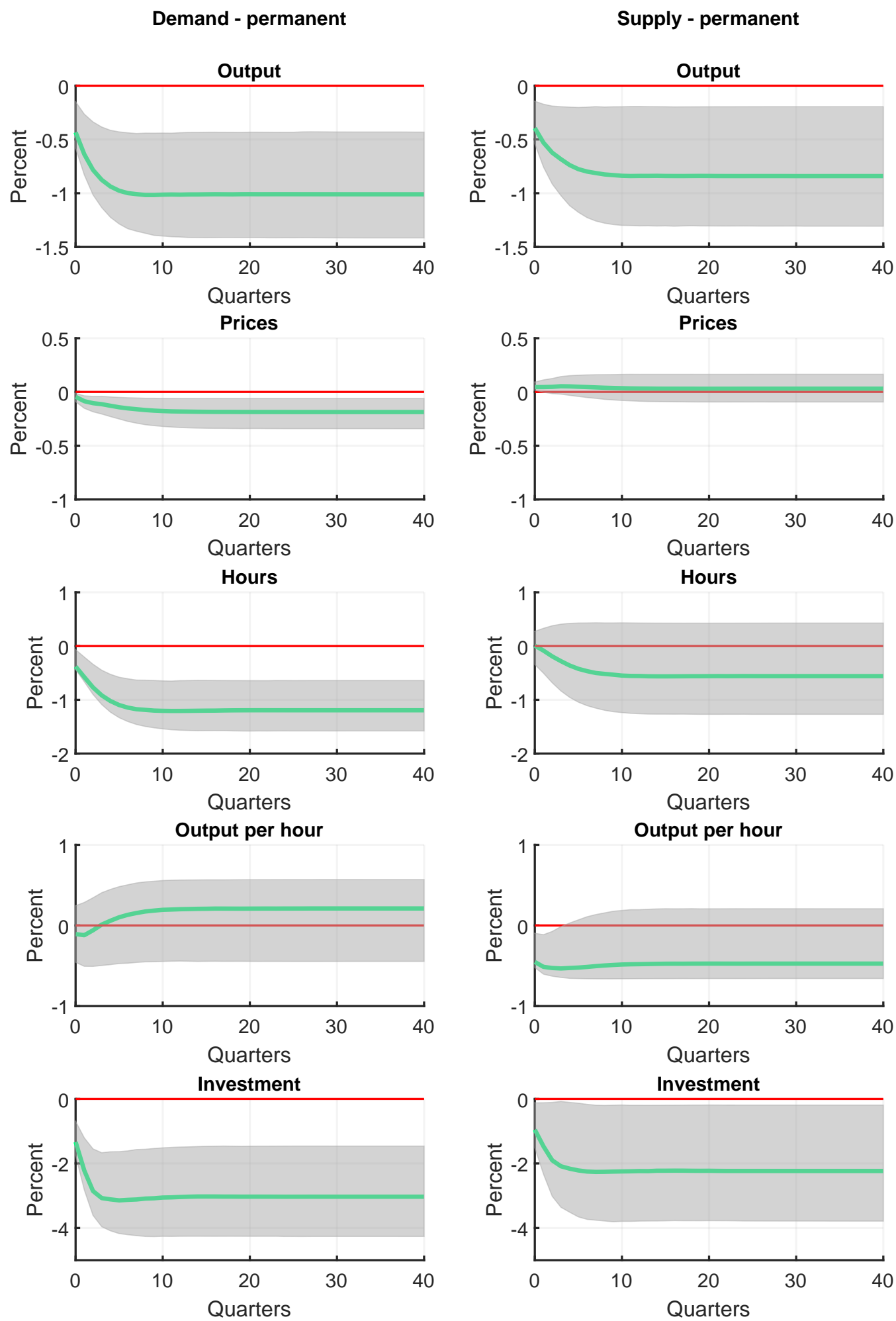
Figure A-4: Forecast error variance decomposition

(Using business sector output and hours)
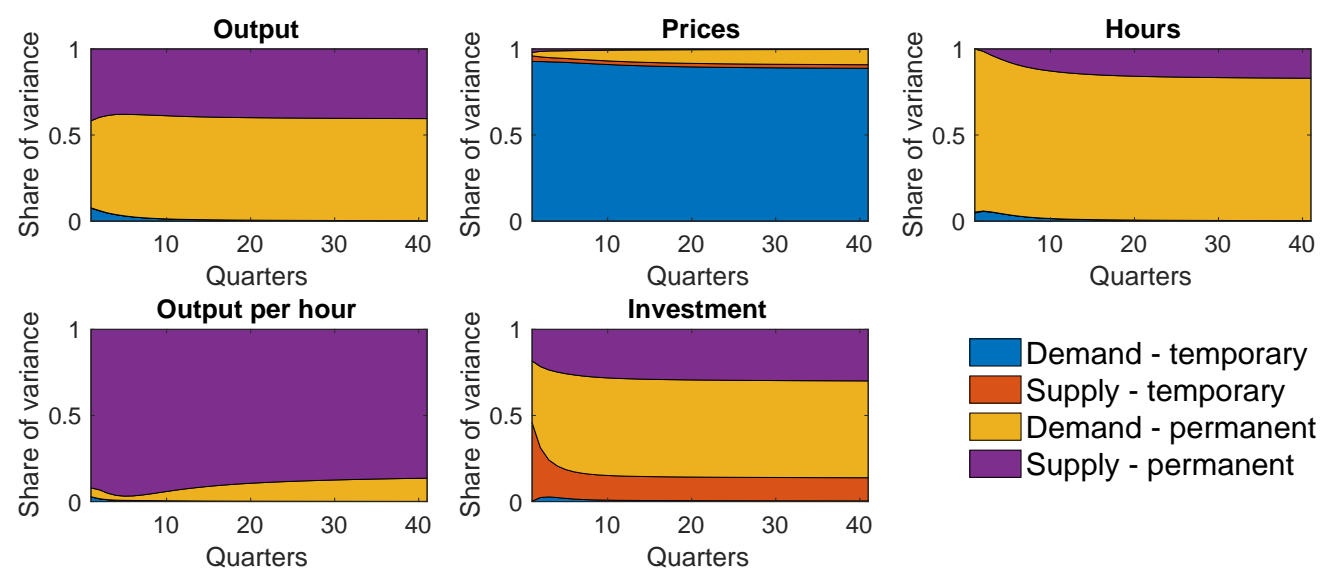

Figure A-5: IRFs and forecast error variance decomposition

(Sign restrictions imposed in the fourth quarter after the shock)
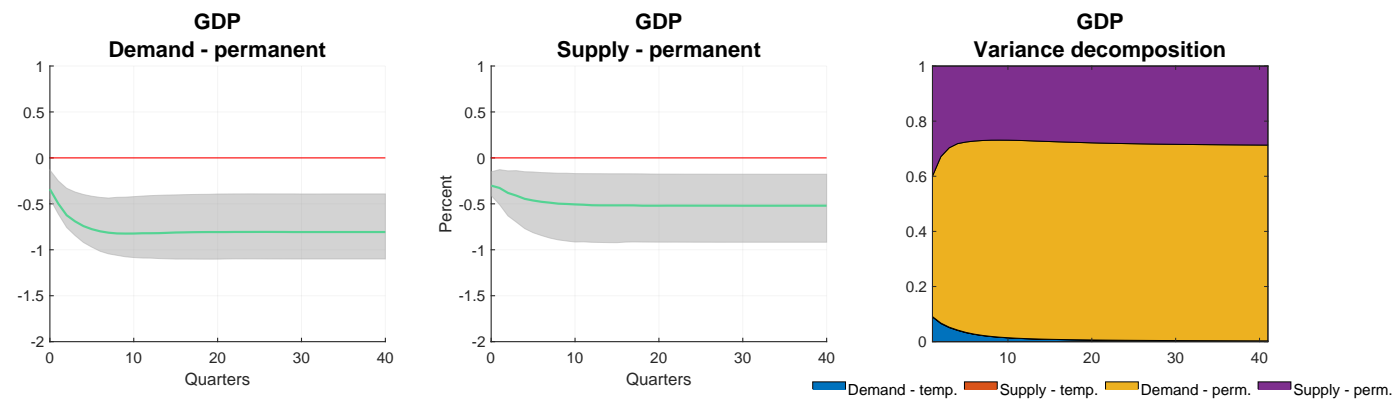